\title{
SISTEMA NACIONAL DE NOTIFICAÇÃO DE EVENTOS ADVERSOS A PRODUTOS DE SAÚDE DA ANVISA: UMA CONTRIBUIÇÃO PARA A AÇÃO EM VIGILÂNCIA EM SAÚDE.
}

\section{GIANE SANT ANA ALVES OLIVEIRA}

TESE APRESENTADA AO DEPARTAMENTO DE PRÁTICA DE SAÚDE PÚBLICA DA FACULDADE DE SAÚDE PÚBLICA DA UNIVERSIDADE DE SÃO PAULO PARA OBTENÇÃO DO TÍTULO DE DOUTOR EM SAÚDE PÚBLICA

ÁREA DE CONCENTRAÇÃO: SERVIÇOS DE SAÚDE

ORIENTADORA: PROF ${ }^{\mathrm{a}}$ DR $^{\mathrm{a}}$ SANDRA MARIA OTTATI DE OLIVEIRA NITRINI

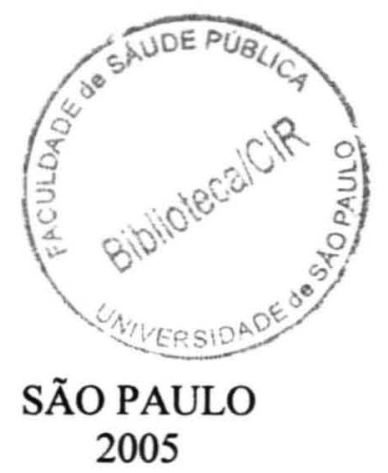


Aos meus filhos

Alan e Artur 


\section{AGRADECIMENTOS}

Agradeço a todo as pessoas que me auxiliaram na progressão deste trabalho, que a propósito foram muitas.

Meu agradecimento especial à minha orientadora Profa Dra Sandra Maria Ottati de Oliveira Nitrini pelo incentivo, principalmente, na fase de conclusão do trabalho.

À minha família especialmente ao meu marido Alberto Alves Oliveira pelo carinho, amor e compreensão nos dias mais pesados.

Aos colegas da Anvisa pela atenção a mim dispensada e por dispor da informação para a realização deste trabalho, especialmente, ao Diretor Presidente da Anvisa Dr.Cláudio Maierovitch P. Henriques, Dra Clarice Alegre Petramale e sua equipe, a Unidade de Farmacovigilância, especialmente, Murilo F. Dias, a Unidade de Tecnovigilância, especialmente, Luiz Eduardo Gonçalves da Costa, e muitos outros colegas dos encontros de gerentes de risco dos hospitais sentinelas.

Aos colegas da SOBRAVIME especialmente, José Ruben Alcântara Bonfim, Ricardo Fernandes de Menezes e Profa Dra Lia Lusitana Cardozo de Castro por dispor sempre de informação atualizada para enriquecer meu trabalho.

Pela grande amizade de Vera Lúcia Mercucci e Nur Shuqair que estão sempre prontas a oferecer auxílio. 


\section{RESUMO}

Oliveira GSA. Sistema Nacional de Notificação de Eventos Adversos a Produtos de Saúde da ANVISA: uma contribuição para a ação em vigilância em saúde. São Paulo; 2005. [Tese de Doutorado - Faculdade de Saúde Pública da USP].

Objetivo. Descrever os eventos adversos relacionados a medicamentos e produtos médicos. Métodos. Realizou-se um estudo descritivo transversal retrospectivo analisando-se as notificações das áreas de farmacovigilância (FVG), queixas técnicas de medicamentos (QTM) e tecnovigilância (TVG) que os hospitais sentinela enviaram para ANVISA coletadas no Sistema Nacional de Notificação de Eventos Adversos a Produtos de Saúde (SINEPS), utilizando-se programa epi-info 6.0. Foi feita uma amostragem das notificações enviadas pelos hospitais sentinelas do Município de São Paulo. Resultados. Dos vinte hospitais sentinelas no Município apenas quatro, sete e oito notificaram neste período para as áreas de FVG, QTM e TVG, respectivamente. Os grupos de medicamentos que mais foram notificados foram os antineoplásicos e imunomoduladores e antimicrobianos para a FVG, os agentes do sangue, sistema cardiovascular e sistema nervoso para QTM e os produtos da categoria de risco II para TVG. Conclusões. Discute-se a preocupação com a subnotificação, e a educação continuada dos profissionais de saúde referente às áreas de estudo. A disponibilidade da informação sobre as notificações para os órgãos executores das ações de vigilância é fundamental, inclusive para que o contato com o notificador esteja mais próximo, possibilitando o retorno das ações realizadas.

Descritores: Eventos adversos. Vigilância em Saúde. Produtos de Saúde. Notificação 


\section{SUMMARY}

Oliveira GSA. National System of Notification of Adverse Events to Health Products of ANVISA: a contribution to action in health vigilance. São Paulo; 2005. [Doctorate thesis - Faculty of Public Health of the State University of São Paulo].

OBJECTIVE. To describe adverse events related to drugs and medical products.

METHODS. A retrospective transversal descriptive study has been carried out by analysing the notifications of the areas of pharmacovigilance, technical complaints of medicines, and technovigilance that the sentinel hospitals have sent to ANVISA collected in the National System of Notification of Adverse Events to Health Products making use of epi.info.6.0 program. A sampling of those notifications was done which has been sent by sentinel hospitals all over São Paulo Municipality. RESULTS. Only four, seven and eight out of twenty sentinel hospitals notified respectively in this period to the areas of pharmachovigilance, technical complaints of medicines and technovigilance. The group of drugs that were most notified were the antineoplasics and immunomodulators and antimicrobials to pharmachovigilance, to the nervous system, cardiovascular system and the blood agents for technical complaints of medicines, and the products of risk II category for technovigilance. CONCLUSIONS. The worry about subnotification is being discussed and the continuous education of the health professionals related to the areas of study.

The availability of information about the notifications of vigilance actions is fundamental, not only for a closer contact with the notifier, but also for the possibility of having feedback from the actions taken previously.

KEYWORDS. Adverse events. Health vigilance. Health Products.Notification 


\section{INDÍCE}

1 -INTRODUÇÃO 08

- $\quad 1.1$-Impacto dos medicamentos no sistema de saúde $\quad 08$ e a farmacovigilância

- 1.2 - Produtos médicos $\quad 19$

- 1.3 - Erros em saúde 22

- 1.4 - Vigilância em saúde 24

2-OBJETIVOS 33

- 2.1 - Objetivo Geral 33

- 2.2-Objetivos específicos 33

3 - MATERIAL E MÉTODO 34

- 3.1 - Delimitação do tema 34

- 3.2 - Tipo de estudo e amostragem 34

- 3.3 - Instrumento de coleta de dados 35

- 3.4 - Banco de dados 36

4 -RESULTADOS E DISCUSSÃO 40

- 4.1 - Descrição geral das notificações 40

- 4.2 - Amostragem: setembro a dezembro de $2004 \quad 50$

- 4.3 - Município de São Paulo 55

- 4.3.1 - Farmacovigilância 55

- 4.3.2 - Investigação de queixa técnica de 61 medicamentos

- 4.3.3 - Tecnovigilância 64

5 - CONCLUSÃO 69

6- CONSIDERAÇÕES FINAIS $\quad 72$ 
7 - REFERÊNCIAS

Anexo 1 - Relação dos hospitais sentinelas

Anexo 2 - Página inicial do SINEPS

Anexo 3 - Modelo de notificação de farmacovigilância

Anexo 4 - Modelo de notificação de tecnovigilância

Anexo 5 - Modelo de notificação de investigação

Anexo 6 - Janela para selecionar amostragem:

farmacovigilância

Anexo 7 - Janela para selecionar amostragem:

tecnovigilância

Anexo 8 - Janela para selecionar amostragem: investigação

Anexo 9 - Definições das categorias de produtos médicos

Anexo 10 - Critérios de risco para produtos médicos 


\section{1 - INTRODUÇÃO}

\section{1 - Impacto dos medicamentos no sistema de saúde e a}

\section{farmacovigilância}

Os medicamentos constituem importantes determinantes da saúde dos indivíduos, mas também podem ser causa de agravos à saúde.

Após a industrialização o número de medicamentos colocados no mercado cresceu geometricamente. Nem sempre representam uma inovação terapêutica e muitas vezes não têm impacto benéfico para a saúde.

Para que os medicamentos tenham impacto positivo para a saúde é fundamental reunir vários fatores: eficácia, qualidade do produto e uso apropriado (racional) do mesmo.

$\mathrm{O}$ uso racional de medicamentos pode ser definido quando os pacientes recebem os medicamentos apropriados às suas necessidades clínicas, em doses adequadas à sua necessidade, por um período de tempo adequado e a um custo acessível para ele e para a comunidade (RAWLINS, 1986).

O uso inadequado (irracional) dos medicamentos contribui para que estes não tenham impacto benéfico para a saúde. A farmacoepidemiologia como utiliza o método epidemiológico para estudar o uso e efeitos dos medicamentos nas populações pode contribuir para o uso racional dos medicamentos (ABAJO, 2001; CASTRO, 2000; CASTRO, 1997).

STROM (2000) definiu Farmacoepidemiologia como o estudo do uso e dos efeitos dos medicamentos em um grande número de pessoas. 
A Organização Mundial da Saúde (OMS) divulgou que mais de $50 \%$ dos medicamentos que são comercializados, prescritos e dispensados no mundo o são de forma inadequada (OMS, 2002).

Vários fatores influem no uso irracional de medicamentos: promoção inadequada, falta de informação independente, as atitudes, crenças e práticas dos profissionais de saúde e dos consumidores, e por ausência no meio acadêmico de uniformidade de critérios quanto ao uso racional de medicamentos (GIACHETTO et al, 2003).

Os gastos efetuados pela indústria farmacêutica em atividades de promoção são elevados e nem sempre estas atividades refletem o uso racional de medicamentos, ao contrário, muitas vezes estão voltados para a ampliação de vendas influenciando o público e, principalmente, tentando alterar os hábitos de prescrição (BARROS, 2004; SANTI, 1999).

Com relação à informação, o estudo de GIACHETTO et al (2003) mostrou que grande parte dos residentes de dois hospitais do Uruguai não tinham conhecimentos suficientes sobre dose, contra-indicações e efeitos adversos dos medicamentos que utilizavam, o que constitui um dos fatores determinantes para uma prescrição irracional. Relata, também, que uma proporção importante de médicos confia na informação de origem comercial como fonte primária para selecionar medicamentos.

As fontes de informação que os profissionais de saúde têm acesso nem sempre são adequadas e muitas vezes são parciais, ressaltando apenas os efeitos benéficos dos medicamentos. No estudo de PONCIANO et al (1998), realizado em um Hospital Universitário do Rio de Janeiro, enfermeiros e médicos consideravam o Dicionário de Especialidades Farmacêuticas (DEF) como instrumento de atualização sobre reações 
adversas a medicamentos. O DEF é uma fonte de informação proveniente da indústria farmacêutica, ou seja, não é uma fonte independente do interesse comercial, portanto não é uma fonte segura para este tipo de avaliação.

MEJÍA e AVALOS (2001) analisaram material de propaganda impresso distribuído aos médicos nos consultórios para avaliar se a informação estava correta e se era acessível. Concluíram que muitas referências citadas estavam incorretas $(45,8 \%)$, e as que estavam corretas, $69 \%$ eram inacessíveis; a ação terapêutica proposta na propaganda correspondia com a bibliografia em somente $70 \%$ dos casos, mas nenhum exemplar mencionava os efeitos adversos e as precauções, portanto, era um material que não poderia ser utilizado como fundamento para realizar uma prescrição racional.

O estudo feito por MASTROIANI et al (2003) analisou a propaganda de medicamentos em periódicos de psiquiatria nacionais, observando que as informações que restringem o uso, como reações adversas, interações, contra - indicações, advertências e precauções, estavam presentes em menor freqüência e num tamanho de letra menor do que as informações que favorecem o uso, contrariando inclusive os regulamentos da vigilância sanitária.

A multiplicação de reações adversas está relacionada diretamente ao uso indevido de medicamentos envolvendo vários aspectos como a propaganda intensiva e enganosa, venda livre, automedicação, baixo nível de informação dos consumidores, preparo insuficiente de prescritores, apresentação científica inadequada dos efeitos indesejáveis e contra-indicações, legislação e fiscalização ineficazes, falhas na qualidade de produção, hipervalorização de medicamentos dentre outros (NASCIMENTO, 2003). 
No mundo, a preocupação com os eventos adversos principalmente, àqueles relacionados a medicamentos é bastante antiga.

Nos Estados Unidos, foi promulgada, em 1906, uma lei em resposta à excessiva adulteração e falsificação de alimentos e medicamentos disponíveis naquela época. Não havia nenhuma restrição à venda ou não se requeria provas de eficácia ou segurança dos medicamentos vendidos. Em 1937, mais de cem pessoas morreram por insuficiência renal como resultado do uso de xarope de sulfanilamida dissolvida em dietilenoglicol (STROM, 2000).

Até a década de 50, pouca atenção foi dada aos efeitos adversos, quando, nos EUA, se descobriu que o cloranfenicol poderia causar anemia aplástica. Em 1952, foi publicado o primeiro livro sobre reações adversas e, no mesmo ano, a Associação Médica Americana estabeleceu o primeiro registro oficial de reações adversas a medicamentos para coletar casos de discrasias sanguíneas induzidas pelos mesmos. Em 1960, a Food and Drug Administration (FDA) iniciou a coleta de notificações de reações adversas e financiou o primeiro programa hospitalar de monitorização intensiva de medicamentos. (STROM, 2000; CASTRO, 2000).

A preocupação com os eventos adversos a medicamentos tomou impulso maior após o desastre da talidomida na década de sessenta, atingindo milhares de pessoas no mundo em função do efeito adverso (focomelia) e, também, anteriormente devido às mortes produzidas pelo xarope de sulfanilamida que continha dietilenoglicol (LAPORTE e TOGNONI, 1993). Após o episódio da talidomida, em 1962, a Assembléia Mundial de Saúde, por meio da resolução 2051, estabeleceu o Sistema Internacional de Monitorização de Reações Adversas a Medicamentos, definido como Farmacovigilância. (NUNES, 2000). 
WOLFE (1999) destaca a extensão do problema relacionado a reações adversas nos Estados Unidos: cada ano, somente em hospitais, há 28 mil casos de toxicidade cardíaca com risco de vida por reações adversas à digoxina. A cada ano, 41 mil idosos são hospitalizados e 3.300 destes morrem por úlceras causadas por anti-inflamatórios não esteroidais. Cada ano mais de 9 milhões e 600 mil reações adversas a medicamentos ocorrem na população idosa americana. Pelo menos 16 mil lesões por acidentes automobilísticos, a cada ano, envolvendo motoristas idosos, nos Estados Unidos, são atribuídos a medicamentos psicoativos, especialmente, benzodiazepínicos e antidepressivos tricíclicos (WOLFE, 1999).

O trabalho de LEVESQUE et al (2004), no Canadá, relata o uso de medicamentos antidiabéticos em idosos e o risco de sofrerem acidentes automobilísticos.

A cada ano 32 mil idosos sofrem de fraturas de quadril, contribuindo para mais de 1.500 mortes atribuídas a quedas induzidas por medicamentos (WOLFE, 1999), também observado no trabalho de ROZENFELD (1997).

Aproximadamente 163 mil idosos americanos sofrem de sérios distúrbios mentais (perda de memória, demência) quer causados ou agravados por medicamentos. Dois milhões de idosos americanos estão dependentes ou em risco de dependência por tranqüilizantes menores ou que induzem ao sono, porque eles usam diariamente por pelo menos 1 ano. Setenta e três mil idosos desenvolveram discinesia tardia induzida por medicamento. Essa condição é a mais séria e mais comum reação adversa a medicamentos antipsicóticos e é freqüentemente irreversível (WOLFE, 1999). 
Sessenta e um mil idosos americanos têm desenvolvido doença de Parkinson induzida por medicamentos devido ao uso de antipsicóticos tais como, haloperidol, tioridazina e flufenazina (WOLFE, 1999).

Não somente os idosos, mas também as crianças são grupos populacionais expostos a este problema (CASTRO, 2004; CARVALHO et al, 2003; KARANDE et al, 2003; KAUCHAL et al, 2001; MENNITI-IPPOLITO et al, 2004), este último grupo, principalmente por sofrer com erros de dosagem e administração (DONOSO e FUENTES, 2004).

O trabalho de SCHMICKLER (2004), realizado na Alemanha, mostra que as análises das notificações no banco de dados, não são eficazes para coletar dados de segurança dos medicamentos utilizados em crianças. Ele acredita que para obter informação detalhada do perfil de segurança em crianças, ferramentas mais sofisticadas devem ser desenvolvidas para serem colocadas nas notificações de vigilância pós comercialização, incluindo informações detalhadas dos padrões de prescrição.

As gestantes e lactantes constituem outro grupo vulnerável (BÉRARD et al, 2004; CHAMBERS et al, 2004; COOPER et al, 2004; HARDY et al, 2004; HEADLEY, 2004; LACROIX et al, 2004; LOUIK et al, 2004; ORAICHI e BÉRARD, 2004; SERREAU et al, 2004; WIHOLM et al, 2004). Estes grupos citados acima não participam dos ensaios préclínicos com medicamentos, sendo esta uma das limitações importantes.

CUNNINGTON et al (2004) relatam que a vigilância pós comercialização para produtos teratogênicos é fragmentada e que estudos de seguimento são mais eficientes para identificar graves teratogenias e estudos de caso - controle são mais eficientes para identificar aumentos em tipos específicos de malformações. É certo que esses estudos 
estabelecem com mais precisão os riscos da associação de um medicamento com uma determinada malformação, entretanto, eles têm um custo mais elevado do que o sistema de notificação espontânea e este não deixa de ser importante, podendo gerar sinais de alerta e direcionar estudos relacionados a problemas importantes para avaliação do risco.

Em 1968, a OMS deu início a um estudo piloto com dez países para a notificação de reações adversas a medicamentos. Atualmente, o Centro de Monitoramento de Reações Adversas a Medicamentos está localizado em Uppsala, na Suécia.

A OMS definia farmacovigilância como o conjunto de procedimentos de deteç̧ão, de registro e de avaliação de reações adversas para determinação de sua incidência, gravidade e de sua relação de causalidade com a forma e a dosagem de um medicamento ou fórmula magistral, com objetivo último de prevenção, com base no estudo sistemático e pluridisciplinar das ações dos medicamentos (CASTRO, 2000).

Em documento mais recente (WHO, 2002a) a OMS reconhece que existe a necessidade para uma reconsideração da prática de farmacovigilância à luz da falta de uma definição clara de fronteiras entre alimentos, medicamentos (tradicionais, produtos naturais e derivados de plantas medicinais), dispositivos médicos e cosméticos.

Desta forma, passou a definir farmacovigilância como a ciência e atividades relacionadas à detecção, avaliação, prevenção e compreensão dos efeitos adversos ou qualquer outro possível problema relacionado a medicamentos. Este conceito tem sido expandido para incluir produtos derivados de plantas medicinais, medicina tradicional e complementar, hemoderivados, produtos biológicos, dispositivos médicos e vacinas.

No mesmo documento especifica os objetivos da farmacovigilância: 
- Melhorar o cuidado e a segurança do paciente em relação ao uso de medicamentos e de todas as intervenções médicas e paramédicas;

- Aperfeiçoar a saúde pública e segurança em relação ao uso de medicamentos;

- Contribuir para a avaliação do benefício, dano, efetividade e risco dos medicamentos, encorajando seu uso seguro, racional e efetivo (incluindo custo-efetividade)

- Promover o entendimento, educação e treinamento clínico em farmacovigilância e sua efetiva comunicação ao público.

Em outro documento a OMS (WHO, 2002b) define reação adversa como uma resposta de um medicamento a qual é prejudicial e não intencional e que ocorre em doses normalmente utilizadas no homem para a profilaxia, diagnóstico, tratamento ou para modificação de uma função fisiológica.

EDWARDS e ARONSON (2000) acreditam que na definição da OMS, a palavra prejudicial (noxious) é imprecisa, ou seja, inclui todas as reações inclusive as leves. Tais inclusões poderiam obstaculizar as operações do Sistema de Vigilância. Desta forma, propõem a seguinte definição para reação adversa a medicamento: "um dano apreciável ou uma reação desprazerosa resultante de uma intervenção relacionada ao uso de um produto medicinal, que prediz risco para a administração futura e requer prevenção ou tratamento específico ou alteração no regime de doses ou retirada do produto".

Nesta definição os autores limitam reações adversas a problemas graves e que possam representar risco futuro. 
Recentemente, também se incluiu mais uma categoria relacionada à classificação das reações adversas, além das categorias classicamente propostas (EDWARDS e ARONSON, 2000): tipo A (relacionada à dose), B (não relacionada à dose) C (relacionada à dose e ao tempo) e $\mathrm{D}$ (relacionada ao tempo), $\mathrm{E}$ (retirada do medicamento) e por último $\mathrm{F}$ (falha terapêutica).

Além de reações adversas a OMS reconhece a importância de trabalhar junto com esta, os problemas relacionados a medicamentos tais como: abuso de medicamentos, uso inadequado, intoxicação, ineficácia terapêutica e erros de medicação. Isto é importante para fazer a diferenciação entre os problemas que em alguns casos não é muito simples.

As intoxicações por medicamentos vêm ocupando há décadas o primeiro lugar nas estatísticas brasileiras. Não se constituem somente como um problema relacionado à tentativa de suicídio, mas também um problema que envolve ingestão acidental em crianças.

O estudo de DIAS (2002), analisou uma amostra de 415 casos de crianças de 0 a 12 anos a partir das fichas que continham dados de acidentes por intoxicação com medicamentos do Centro de Informações Toxicológicas de Goiás, entre 1998 e 2000. Mostrou que quase a totalidade dos casos notificados estavam na faixa etária de 1 a 4 anos e sempre advinham de ingestões acidentais voluntárias.

No Brasil, ainda são muito comuns os problemas relacionados com queixas técnicas de medicamentos que podem englobar: corpo estranho, má dissolução, problemas de rotulagem, ineficácia terapêutica, dentre outros. Um estudo feito por LUNA e colaboradores (2002) analisaram amostras de medicamentos na forma de soluções e suspensões orais coletadas entre 1998 e 2001 pela vigilância sanitária, encontrando 72,5\% 
de produtos insatisfatórios, incluindo aqueles relacionados ao aspecto, teor do princípio ativo e em relação à análise microbiológica. Com relação a problemas na rotulagem este percentual subiu para aproximadamente $91 \%$.

Outros estudos também relatam problemas de qualidade com os produtos farmacêuticos incluindo imunobiológicos, hemoderivados, fitoterápicos e até falsificações (ADATI et al, 2002 a; 2002 b; BISPO et al, 2002; GOMES et al, 2002; GUERRA Jr et al, 2002; LACERDA et al, 2002; MIRANDA e ROZENFELD, 2002; STEPHENS et al, 2002).

Embora não exista ainda uma harmonização internacional, alguns termos são utilizados para caracterizar os problemas relacionados a medicamentos. Por exemplo, em espanhol é muito mais freqüente utilizar o termo "acontecimento" do que evento (NAVARRO, 2002).

O grupo RUIZ-JARABO et al (2000) define acontecimentos adversos por medicamentos a qualquer dano pelo uso terapêutico, incluindo a falta de uso, de um medicamento.

A OMS (WHO, 2002b) define evento adverso como qualquer ocorrência médica que se apresenta durante o tratamento com um produto medicinal, mas que não tem necessariamente uma relação causal com o tratamento. LAURENCE e CARPENTER (1994) definem como a OMS, mas referem à ocorrência também em ensaios clínicos.

$\mathrm{Na}$ realização das atividades de farmacovigilância depara-se com diversos problemas: prescrição inadequada, administração, dose e via de administração inadequadas, pouco aprofundamento da história farmacológica do paciente, monitoramento inadequado de medicamentos e de outras provas de laboratório, interações medicamentosas, desconhecimento de conceitos de farmacocinética e farmacodinâmica (SEGURA e 
MALDONADO, 2003) além de problemas relacionados à qualidade de produtos farmacêuticos: rotulagem, teor de princípio ativo, contaminação etc.

A farmacovigilância deve identificar eventos adversos relacionados a medicamentos, analisá-los e gerar estratégias de prevenção (SEGURA e MALDONADO, 2003). Contribui para que reações adversas graves desconhecidas e de ocorrência rara a medicamentos novos ou antigos possam ser identificadas e prevenidas (COÊLHO, 1998; MACKAY, 2004), possibilita também comparar padrões diferentes de respostas aos medicamentos entre as populações dos países (KOO e CLARK, 2004).

Vários estudos têm mostrado as reações adversas a medicamentos (RAM) como causa importante de hospitalização (BERTULYTE e GULBINOVIC, 2004; DORMANN et al, 2003; PFAFFENBACH et al, 2002) com proporções que variam entre 0,9 e $28 \%$; como causa de morte, como evento adverso em pacientes hospitalizados (DOMÍNGUEZ et al, 2004; LOURO, 2004) com uma proporção entre 1,5 e 43,5\% de RAM e com incidência na população geral de 3,2\%. Isso representa um aumento nos custos com a saúde, principalmente quando a RAM eleva o aumento dos dias de estadia hospitalar além de exames, medicamentos e custos indiretos (SEGURA e MALDONADO, 2003).

$\mathrm{Na}$ revisão da literatura realizada por SEGURA e MALDONADO (2003), foi detectada uma morbidade hospitalar (média dos estudos) em torno de $14 \%$ e mortalidade hospitalar em $2 \%$ dos eventos com medicamentos e o impacto de prevenir eventos adversos a medicamentos significa uma redução de custos da atenção médica de até $60 \%$.

O conhecimento e a busca de reações adversas é fundamental para monitorar o tratamento e permitir a identificação e notificação de eventos adversos, contribuindo para o desenvolvimento da farmacovigilância (GIACHETTO et al, 2003). 
Ademais, as notificações de reações adversas contribuem para o uso racional de medicamentos, porque além de contribuir para a segurança, qualidade e eficácia destes, também podem identificar reações desconhecidas ou pouco descritas na literatura, realizar investigações farmacoepidemiológicas em grupos mais susceptíveis e apoiar e subsidiar as autoridades sanitárias para tomada de decisões quanto à solução de problemas relativos à segurança, qualidade e efetividade dos medicamentos (ZUBIOLI, 2004).

\section{2 - Produtos médicos}

A segurança de produtos médicos para a saúde ou dispositivos médicos começou a ter importância maior, no Brasil, recentemente.

Historicamente, as ações de vigilância sanitária foram direcionadas para as questões referentes a meio ambiente, alimentos e medicamentos. Com a adoção de novas tecnologias na prática médica, exigiu-se da vigilância sanitária mais um campo de atuação com o intuito de garantir que os produtos destinados à prática médica e laboratorial fossem seguros e eficazes. No âmbito federal, nos últimos anos, os produtos para a saúde passaram a ser tratados por profissionais especializados e regidos por normas mais específicas quanto ao registro e verificação de Boas Práticas de Fabricação ${ }^{1}$ (VALENTE et al, 2002).

A segurança sanitária destes produtos engloba a conformidade, eficácia e efetividade. O Programa Brasileiro de Avaliação e Conformidade do Instituto Nacional de Metrologia, Normalização e Qualidade Industrial (INMETRO) do Ministério do

\footnotetext{
${ }^{1}$ * A OMS define Boas Práticas de Fabricação como um sistema para assegurar que os produtos sejam consistentemente produzidos e controlados de acordo com os padrões de qualidade. (WHO, 2005).
} 
Desenvolvimento, Indústria e Comércio Exterior, é um instrumento para os órgãos de fiscalização para avaliar e garantir os requisitos de segurança e qualidade dos equipamentos eletromédicos, determinando os tipos de equipamentos passíveis de certificação de conformidade (ARAÚJO, 2002).

Entende-se por "conformidade" o cumprimento das normas técnicas que se aplicam aos produtos para a correta execução das funções prometidas. Eficácia é o efeito que resulta do uso do produto em condições controladas (informações obtidas em estudos clínicos nas fases I, II e III). Efetividade é o efeito obtido quando se está utilizando o produto durante os serviços de rotina (informação obtida em condições não padronizadas, denominadas estudos da fase IV) (ANTUNES et al, 2002).

Produto médico: Produto para a saúde, tal como equipamento, aparelho, material, artigo ou sistema de uso ou aplicação médica, odontológica ou laboratorial, destinado à prevenção, diagnóstico, tratamento, reabilitação ou anticoncepção e que não utiliza meio farmacológico, imunológico ou metabólico para realizar sua principal função em seres humanos podendo, entretanto, ser auxiliado em suas funções por tais meios (MINISTÉRIO DA SAÚDE, 1994; ANVISA, 2001b).

As definições de cada categoria de produtos médicos estão descritas no anexo nove.

Muitos problemas têm sido descritos na literatura mundial relacionados a produtos médicos, além da preocupação com a segurança do paciente (BROWN e WOO, 2004; CHAN et al, 2000; GHERARDINI et al, 2004; GREENFIELD, 2004; SAMORE et al, 2004; SMALL, 2004). Os alertas da Agência Nacional de Vigilância Sanitária (ANVISA, 2005a) retratam a situação: a retirada do mercado de reagentes para diagnóstico que proporcionavam resultados falso positivo ou falso negativo; risco de choque elétrico com 
equipamento médico; problema com o software de equipamentos médicos; graduação incorreta de seringas, dentre outros.

Recentemente, a ANVISA proibiu a utilização de medidores mamários de silicone, utilizados em cirurgia para reconstituição da mama ou estética. Várias notificações relataram a ocorrência de eventos adversos que após análise bacteriológica detectou-se a presença de Mycobacterium fortuitum (ANVISA, 2005b).

MAISEL (2004) destaca o papel da Food and Drug Administration (FDA), agência de regulação americana no sentido de ser a responsável pela segurança e efetividade destes produtos e como os médicos podem contribuir realizando pesquisas e comunicando os eventos adversos, já que estes produtos são utilizados largamente na prática médica. Relata que nos anos oitenta os fabricantes eram criticados por comunicação inadequada de eventos adversos ao FDA e falharam ao conduzir o recolhimento apropriado dos produtos. Cita o exemplo da retirada do mercado de válvula mecânica do coração por causa de uma falha prematura, afetando mais de 400 pacientes.

Um outro problema com estes produtos é o reprocessamento, comum em várias instituições de saúde. No estudo feito por TARASKA (2002) sobre a validação do processo de reprocessamento e esterilidade de tampinhas utilizadas para fechar as linhas arteriais e venosas dos pacientes submetidos à hemodiálise, mostrou que algumas apresentaram crescimento de microorganismos após o reprocessamento.

Reprocessamento é o processo a ser aplicado a artigos médico-hospitalares, exceto os de uso único, para permitir sua reutilização incluindo a limpeza, desinfecção, preparo, embalagem, esterilização e controle de qualidade (Ministério da Saúde e Ministério do Trabalho e Emprego, 1999). 
A Lei $\mathrm{n}^{\circ} 6360$ de 26 de setembro de 1976 (BRASIl, 1976), prevê o registro destes produtos e, posteriormente, foi regulamentada pela Portaria n 2661/95 (MINISTÉRIO DA SAÚDE, 1995) e pela RDC 185 (ANVISA, 2001b) que os enquadra segundo critérios de risco em classes I, II, III e IV conforme descrito no anexo 10.

Apesar de toda regulamentação esses produtos, após comercialização, como os medicamentos, podem proporcionar riscos que podem ameaçar a segurança dos pacientes.

Recentemente, a ANVISA identificou várias empresas clandestinas na área de implantes ortopédicos que integravam uma rede de fornecedores de seus produtos para diversos hospitais (SILVA, 2002).

A tecnovigilância tem por objetivo a vigilância dos acidentes, ou riscos de acidentes que resultam da utilização de produtos médicos e equipamentos biomédicos depois de sua colocação no mercado (ANTUNES et al, 2002).

\section{3 - Erros em saúde}

Erros médicos podem ser definidos como falha de uma ação planejada que deve ser realizada de acordo com uma determinada intenção ou a utilização de um plano inapropriado para atingir um determinado objetivo, podendo incluir problemas relacionados à prática, produtos, procedimentos ou sistemas. Os quase erros são definidos como falhas que não resultam em lesão ou dano (CASSIANI e UETA, 2004).

Nos Estados Unidos o Instituto de Medicina, divulgou em 1999, um relatório afirmando que mais pessoas morrem como resultado de erros médicos do que em 
conseqüência de acidentes de trânsito, câncer de mama ou AIDS (CASSIANI e UETA, 2004).

Dentro dos erros médicos e de outros profissionais, os erros com medicação são bastante comuns. Estes erros podem ser de prescrição inadequada, dispensação, administração e uso de medicamentos.

LÓPEZ (2003) discute em seu trabalho que errar é um fenômeno inerente à natureza humana e que, por isso, necessitamos criar sistemas sanitários seguros que sejam resistentes aos erros humanos, ou seja, que ajudem a preveni-los, a identificá-los e a minimizar suas conseqüências.

SANTOS (2002) realizou um estudo em 15 hospitais gerais, do município de São Paulo, evidenciando a problemática relacionada a eventos adversos com medicamentos, inclusive erros e a grande preocupação dos enfermeiros com este fato. Dos enfermeiros participantes $29,3 \%$ eram de instituições públicas, $67,2 \%$ de entidades privadas e $3,5 \%$ de entidades mantenedoras mistas. Quanto à freqüência com que os enfermeiros depararam-se com eventos adversos com medicação em sua vida profissional, $47 \%$ deles referiram ter vivenciado algumas vezes essa situação, $48 \%$ apontaram como raramente e $4 \%$ informaram não terem vivido essa experiência nenhuma vez.

O estudo de SANTOS (2002) também relata as condutas dos enfermeiros frente ao evento adverso, seus sentimentos e os fatores predisponentes à ocorrência dos mesmos. Com relação às condutas, $33 \%$ dos enfermeiros relataram que comunicavam o médico, $30 \%$ intensificavam os cuidados, $13 \%$ repreenderam o funcionário, $12 \%$ anotavam no prontuário e $8 \%$ avisavam a chefia imediata. Quanto ao sentimento referido frente ao evento adverso, $35 \%$ relataram preocupação, $16 \%$ insegurança, $14 \%$ impotência, $14 \%$ raiva e $12 \%$ culpa. 
Os fatores predisponentes à ocorrência de eventos adversos foram: desatenção (29\%), prescrição médica ilegível (16\%), sobrecarga de trabalho (16\%), displicência do funcionário $(16 \%)$ dentre outros.

Danos iatrogênicos, em geral, e aqueles resultantes da administração de medicamentos, em particular, apresentam importantes conseqüências econômicas e os vários estudos sobre a epidemiologia dos erros na medicação e os eventos adversos a medicamentos em contextos de pacientes internados, ambulatoriais, pediátricos e geriátricos, demonstram que estas questões são amplas e têm impacto substancial sobre os indivíduos (CASSIANI e UETA, 2004; SANTELL et al, 2003; WEINGART et al, 2000).

Para os produtos médico hospitalares, HOLSBACH et al (2002) relatam que o acidente no ambiente hospitalar, onde se utiliza com mais frequiência equipamentos e instrumentos mais sofisticados, é fato. Ressaltam a importância do desenvolvimento de uma metodologia para a investigação de acidentes com equipamentos médicos, principalmente em ambientes cirúrgicos, que deve contemplar as seguintes etapas: preservação das evidências, coleta de informações, metodologia de investigação, banco de dados, sugestão de ações corretivas, disseminação de informações sobre problemas e soluções encontradas e ações educativas para a prevenção.

\section{4 - A vigilância em saúde e os eventos adversos}

A vigilância de problemas de saúde é bastante antiga, desde problemas relacionados a enfermidades transmissíveis, preocupação com os alimentos, água, boticas, esgoto, lixo, exercício profissional, educação sanitária dentre outros (COSTA, 2004; SOUTO, 2004). 
Um marco importante da vigilância sanitária no Brasil, foi a criação, em 1976, da Secretaria Nacional de Vigilância Sanitária (SNVS), órgão do Ministério da Saúde.

Em 1988, com a promulgação da Constituição Brasileira, a área de saúde inicia uma nova etapa com o Sistema Único de Saúde, SUS, (BRASIL, 2001), organizado descentralizadamente, com atendimento integral e com a participação da comunidade (artigo 198). A Constituição, em seu artigo 200, fala da competência do SUS, onde incorpora o controle e fiscalização de procedimentos, produtos e substâncias de interesse para a saúde e execução de ações de vigilância sanitária, epidemiológica, bem como as de saúde do trabalhador dentre outras atribuições.

A Lei 8080 (1990), dispõe sobre as condições para a promoção, proteção e recuperação da saúde, a organização e o funcionamento dos serviços (GOUVEIA, 2000). Em seu artigo $6^{\circ}$ reitera como atribuição do SUS, a execução das ações de vigilância sanitária, epidemiológica, o controle e físcalização de serviços, produtos e substâncias de interesse para a saúde. Define vigilância sanitária e epidemiológica nos parágrafos $1^{\circ}$ e $2^{\circ}$ respectivamente, do artigo $6^{\circ}$ :

$\S 1^{\circ}$ Entende-se por vigilância sanitária um conjunto de ações capaz de eliminar, diminuir ou prevenir riscos à saúde e de intervir nos problemas sanitários decorrentes do meio ambiente, da produção e circulação de bens e da prestação de serviços de interesse da saúde, abrangendo:

I - o controle de bens de consumo que, direta ou indiretamente, se relacionem com a saúde, compreendidas todas as etapas e processos, da produção ao consumo;

II - o controle da prestação de serviços que se relacionam direta ou indiretamente com a saúde. 
$\S 2^{0}$ Entende-se por vigilância epidemiológica um conjunto de ações que proporcionam o conhecimento, a detecção ou prevenção de qualquer mudança nos fatores determinantes e condicionantes de saúde individual ou coletiva, com a finalidade de recomendar e adotar as medidas de prevenção e controle das doenças ou agravos.

A definição de vigilância sanitária colocada nesta lei introduz o conceito de risco ao contrário da definição anterior, de 1998, de caráter eminentemente burocrático e normativo (Rozenfeld, 2000).

Uma outra definição interessante foi colocada por EDUARDO (1998): "vigilância sanitária é um conjunto de ações no âmbito das práticas de saúde coletiva, assentadas em várias áreas do conhecimento técnico científico e em bases jurídicas que lhe conferem o poder de normatização, educação, avaliação e de intervenção e que tem por objetivo sontrolar e garantir a qualidade dos processos tecnológicos utilizados na produção e eprodução das condições de vida, trabalho e saúde dos cidadãos".

A própria epidemiologia passou de um interesse exclusivo nas epidemias de loenças infecciosas, para incorporar as doenças não infecciosas e, posteriormente, a ivaliação de serviços e tecnologias de saúde e os agravos resultantes das diversas formas de violência, já na perspectiva de uma epidemiologia dos fatores de risco (SEVALHO, 1998).

Entende-se que para trabalhar com eventos adversos relacionados à saúde utiliza-se ss conceitos de vigilância sanitária e de vigilância epidemiológica, portanto acredita-se que , termo vigilância à saúde possa expressar melhor esta compreensão.

SEVALHO (1998) aponta para o conceito de vigilância em saúde de Tracker \& 3erkelman: "a coleta, análise e interpretação sistemáticas e permanentes de dados sobre aaúde pública, integradas à pronta disseminação dos dados a todos aqueles que devem 
conhecê-los. Sendo que as caracteristicas principais que identificam e fundamentam um sistema de vigilância são: a descrição, acompanhamento, a continuidade ou permanência, a sistematização e divulgação das informações, ou seja é um sistema de informações para a ação que tem por objetivo principal acompanhar eventos definidos e, se necessário, intervir oportunamente em seu curso".

Outro marco importante na área regulatória foi a promulgação da Lei 9782/99 (BRASIL, 1999) que dispõe sobre o Sistema Nacional de Vigilância Sanitária e cria a Agência Nacional de Vigilância Sanitária, autarquia especial, vinculada ao Ministério da Saúde tendo como finalidade institucional promover a proteção da saúde da população, por intermédio do controle sanitário da produção e da comercialização de produtos e serviços submetidos à vigilância sanitária, inclusive dos ambientes, dos processos, dos insumos e das tecnologias a eles relacionados, bem como o controle de portos, aeroportos e fronteiras.

No Brasil, a Lei Federal 6360/76 (BRASIL, 1976) em seu artigo 79 jả apontava para a notificação de problemas relacionados a medicamentos: "todos os informes sobre acidentes ou reações nocivas causadas por medicamentos serão transmitidos à autoridade sanitária competente".

Segundo ROZENFELD (1998) os medicamentos estão entre os produtos mais pesadamente regulamentados, em parte devido ao impacto da difusão dos eventos adversos, embora, o impulso inicial da regulamentação tenha derivado da necessidade de normatizar a competição entre os fabricantes, quanto aos nomes de marca, por exemplo, e depois evoluindo para a proteção dos consumidores contra fraudes e para incorporação dos resultados dos estudos epidemiológicos. 
O Decreto 3029 de 16 de abril de 1999 (BRASIL, 1999), que aprova o regulamento da Agência Nacional de Vigilância Sanitária, reitera no artigo $3^{\circ}$ inciso XVI, a competência dada pela Lei 9782/99, da Agência, para estabelecer, coordenar e monitorar os sistemas de vigilância toxicológica e farmacológica.

A resolução $n^{\circ} 1$ de 26 de abril de 1999 (ANVISA, 1999) que aprova o regimento e quadro de distribuição de cargos em comissões e funções comissionadas de vigilância sanitária, estabelecia, em vários artigos, as competências de diversas gerências da ANVISA para trabalharem com eventos adversos, inclusive com produtos médicos: gerência geral do sistema nacional de registro de reações adversas; gerência geral de correlatos; gerência de pesquisa e análise de efeitos adversos; gerência geral de medicamentos; gerência de farmacovigilância e gerência geral de toxicologia.

As ações relacionadas a eventos adversos a produtos estavam pulverizadas em várias gerências.

A conformação do Sistema, hoje, já está diferente com a publicação da Portaria $\mathbf{n}^{\circ}$ 593 de 25 de agosto de 2000 (ANVISA, 2000), que atualiza o regimento interno da Agência, transformando algumas gerências em unidades de uma gerência. Esta Portaria foi atualizada pelas Portaria $\mathrm{n}^{\circ} 385$, de 4 de junho de 2003 (ANVISA, 2003), Portaria $\mathrm{n}^{\circ} 239$, de 17 de maio de 2001 (ANVISA, 2001) e Portaria ${ }^{\circ}$ 123, de 09 de fevereiro de 2004 (ANVISA, 2004).

Tem-se hoje a Unidade de Farmacovigilância, ligada à gerência Geral de Medicamentos que trabalha com as reações adversas a medicamentos, inclusive com ineficácia terapêutica. 
O Brasil foi admitido em agosto de 2001, pela OMS, como o $62^{\circ}$ país a fazer parte do Programa Internacional de Monitorização de Medicamentos, coordenado pelo The Uppsala Monitoring Center - WHO Collaborating Centre for International Drug Monitoring, localizado na Suécia. Neste contexto, o Brasil passa a ser membro oficial do programa, sediado na Unidade de Farmacovigilância da ANVISA.

Outras Gerências da ANVISA, investigam os eventos adversos relacionados à queixas técnicas de medicamentos e a produtos médicos.

A Política vigente hoje para a regulamentação de medicamentos no Brasil (ANVISA 2004b) está centrada nos seguintes pontos:

- Reconhecimento de três categorias principais para o registro de medicamentos (homeopáticos, fitoterápicos e substâncias quimicamente definidas);

- Verificação da qualidade quanto à reprodutibilidade (igualdade entre lotes), segurança e eficácia terapêutica dos medicamentos dentro das três categorias, por meio de comprovação laboratorial ou de estudos clínicos;

- Controle da matéria prima;

- Redefinição das categorias de venda para medicamentos: isentos da prescrição médica, com prescrição médica e controlados;

- Exigência da certificação de Boas Práticas de Fabricação para a concessão de registro para a linha de produção de medicamentos;

- Redução da assimetria de informação (diferenças dos níveis de informação na cadeia prescritor-farmácia-paciente) e aumento do controle sobre o direcionamento e conteúdo adequados da propaganda de medicamentos; 
- Aumento do controle da venda de medicamentos de tarja preta ;

- Participação nas estratégias que facilitam o acesso a medicamentos pela maioria da população;

- Informatização e desburocratização do processo de registro e da alterações pós registro;

- Ampliação do monitoramento da qualidade dos medicamentos em comercialização;

- Redução do número de associações irracionais;

- Reforço na fiscalização quanto à utilização de nomes comerciais pelos fabricantes que possam induzir erros de prescrição e automedicação.

Uma das estratégias da ANVISA para implementar a notificação de eventos adversos foi a estratégia de hospitais sentinelas adotada em 2001 pela Gerência de Vigilância em Serviços de Saúde, adotando a idéia de gerência de risco nos hospitais. No primeiro momento, reuniu 100 grandes hospitais do Brasil que indicavam o gerente de risco para treinamento ministrado pela Agência.

Os critérios de seleção dos hospitais privilegiaram a escolha de hospitais de grande e médio porte, que realizam ampla gama de procedimentos com a participação de tecnologias médicas variadas e complexas além de desenvolvem programas de residência médica.

Para a implantação do Projeto Hospitais Sentinela foram desenvolvidas oficinas de capacitação para profissionais de saúde: médicos, enfermeiros, farmacêuticos, engenheiros, de áreas hospitalares, para constituição do núcleo da Gerência de Risco Sanitário e 
Hospitalar. Estes hospitais também receberam ajuda financeira mediante apresentação de algumas contrapartidas. $\mathrm{O}$ anexo 1 mostra a relação de hospitais sentinelas.

Em maio de 2003 foi colocado em prática o Sistema de Informação de Notificação de Eventos Adversos e Queixas Técnicas relacionados a Produtos de Saúde (SINEPS), nas áreas de Farmacovigilância, Hemovigilância e Tecnovigilância que os Gerentes de Risco Sanitário Hospitalar do Projeto Hospitais Sentinela e Colaboradores passaram a utilizar. A notificação é feita eletronicamente e enviada diretamente para a ANVISA. O SINEPS já passou por várias revisões e hoje está na versão $1.6 \mathrm{~b}$ que inclui também a área de queixa técnica de medicamentos.

Os produtos que podem ser notificados através do SINEPS são: medicamentos, equipamentos de diagnóstico, de terapia e de apoio médico hospitalar, materiais descartáveis, implantáveis e de apoio médico hospitalar, materiais e produtos de diagnóstico de uso in vitro, sangue e seus componentes e saneantes de uso hospitalar.

Compete à função de Gerente de Risco Sanitário Hospitalar:

- Desenvolver e estimular ações de Vigilância Sanitária Hospitalar, com conhecimento para auxiliar a seleção, o planejamento e a gerência dos produtos para saúde;

- Auxiliar a identificar, investigar e enviar as notificações de eventos, incidentes, reações adversas, ou queixa técnicas associados aos medicamentos, sangue e hemoderivados, equipamentos e artigos de uso médico, reagentes para 
diagnóstico de uso in vitro e materiais para desinfecção e esterilização em ambiente hospitalar com suspeita de envolvimento de produtos para a saúde à Anvisa;

- Coordenar as ações requeridas em Tecnovigilância, Farmacovigilância e Hemovigilância e Vigilância de Saneantes de Uso Hospitalar;

- Participar da formação, disseminação dos conhecimentos e atualização de recursos humanos em Tecnovigilância, Farmacovigilância, Hemovigilância e materiais para desinfecção e esterilização em ambiente hospitalar (ANVISA, 2005c). 


\section{2 - OBJETIVOS}

\section{1 - Geral}

- Descrever os eventos adversos provocados por medicamentos (reações adversas e queixas técnicas) e produtos médicos, no universo de notificações recebidas pela Agência Nacional de Vigilância Sanitária (ANVISA).

\section{2 - Específicos}

- Descrever o perfil de notificações de medicamentos e de produtos médicos que foram enviadas pelos hospitais sentinelas à Anvisa;

- Apresentar a relação causal entre a suspeita e o medicamento envolvido;

- Apresentar a gravidade, dos efeitos produzidos pela reação adversa ao medicamento; 


\section{3 - MATERIAL E MÉTODO}

\section{1 - Delimitação do tema}

Neste trabalho restringe-se os eventos adversos a produtos englobando os nedicamentos (reação adversa e queixa técnica) e produtos médicos, ou seja, exclui-se os :ventos relacionados a hemocomponentes, por se tratar de metodologia diferente que a ANVISA utiliza na captação destes eventos, relacionadas a saneantes, cosméticos, ılimentos e as intoxicações.

\section{2- Tipo de estudo e amostragem}

Realizou-se um estudo descritivo transversal retrospectivo, mediante a análise das 1otificações das áreas de farmacovigilância, investigação de queixa técnica a medicamentos : tecnovigilância recebidas dos hospitais sentinelas pela Agência Nacional de Vigilância janitária (ANVISA).

O número total de hospitais sentinelas é de noventa e nove (99), sendo trinta e um 31) no Estado de São Paulo e vinte (20) estão na capital (Anexo 1).

Foi feita uma análise geral de todas as notificações disponíveis no SINEPS, quanto I número de notificações recebidas em cada uma das três áreas, distribuição por Estados da Federação e segundo meses do ano e empresas (identificadas por códigos) com maior 
ıúmero de queixas técnicas relacionadas a medicamentos e a produtos médicos (anexos 6, 7 $28)$.

Para especificar melhor cada notificação, foi feita uma amostragem de todas as notificações que estavam no SINEPS enviadas pelos hospitais sentinelas do município de São Paulo, nos 4 últimos meses do ano de 2004 (setembro a dezembro).

O período de amostragem se justifica pois, segundo a ANVISA o ano de 2004 foi responsável por $39 \%$ das notificações existentes na Unidade de Farmacovigilância (DIAS,2005), além do aprimoramento do sistema de notificações feito pela ANVISA e na melhoria da qualidade destas após três anos de implantação do sistema.

\section{3- Instrumento de coleta de dados}

Como instrumento de coleta de dados foram utilizadas as fichas de notificações de eventos adversos relacionadas a medicamentos (farmacovigilância e queixa técnica) e os eventos adversos relacionados a produtos para saúde (tecnovigilância).

As notificações foram captadas pelo sistema de auditoria da ANVISA (www.anvisa.gov.br/sineps) por meio de uma senha fornecida pela Agência para acessar o sistema. $\mathrm{O}$ anexo dois (2) mostra a página inicial deste sistema.

Os anexos três (3), quatro (4) e cinco (5) mostram, respectivamente, o modelo das notificações de farmacovigilância, tecnovigilância e investigação de queixas técnicas.

Para cada uma destas três áreas foi feita a seleção por mês de acordo com a amostragem (Anexos 6 e 7). Na área de investigação de queixa técnica o filtro foi feito a 
partir dos dados de todas as notificações de 2004 (Anexo 8) pois, não havia a possibilidade de seleção direta, para depois fazer a seleção de acordo com a amostragem.

A partir dos dados de todos os hospitais, foram selecionadas as notificações dos hospitais de São Paulo para entrada de dados no programa epi-info 6.0 (CDC, 2005).

Alguns problemas foram verificados com relação às notificações: havia notificação em duplicata que o sistema ainda as mantinham, e outras notificações que não estavam disponíveis no sistema.

$\mathrm{Na}$ área de farmacovigilância, o SINEPS computava 32 notificações dos hospitais sentinelas do município de São Paulo, no período de setembro a dezembro de 2004, entretanto, conseguiu-se localizar 25 (78\%) e destas, 4 estavam repetidas, ou seja, o mesmo caso enviado mais de uma vez. $\mathrm{O}$ total de fichas de notificação para a amostragem foi de 21 (vinte e uma).

$\mathrm{Na}$ área de investigação de queixa técnica de medicamentos o sistema apontava 71 notificações, encontrou-se 59 (83\%) e destas, 3 estavam repetidas. O total de fichas de notificação para a amostragem foi de 56 (cinqüenta e seis).

$\mathrm{Na}$ área de tecnovigilância o sistema computava 170 notificações dos hospitais sentinelas do município de São Paulo, no período citado, entretanto, encontramos 163 $(95,8 \%)$ notificações, sendo que 57 estavam repetidas, totalizando uma amostra de 106 notificações.

\section{4 - Banco de dados}

O banco de dados foi montado com o auxílio do programa Epi-info 6.0. 
As variáveis consideradas para notificação da farmacovigilância foram: mês da notificação, categoria profissional do notificador (médico, farmacêutico, enfermeiro ou outro profissional), se é a primeira notificação ou seguimento de caso, se a indústria foi notificada, idade e sexo do paciente, medicamento suspeito classificado por grupo farmacológico segundo a classificação anatômico terapêutica (ATC) (WHOc 2005), história de alergia e de patologias concomitantes, descrição da reação adversa, dados sobre condutas, evolução e apresentação da causalidade.

A avaliação da causalidade é feita pelo próprio gerente de risco dos hospitais sentinelas. O instrumento utilizado foi o preconizado pela OMS (UPPSALA, 2005), conforme descrição abaixo.

Categorias de causalidade:

Definida: Um evento clínico, incluindo anormalidades de exames laboratoriais, ocorrendo em um espaço de tempo plausível em relação à administração do medicamento, e que não pode ser explicado pela doença de base ou por outros medicamentos ou mesmo substâncias químicas. A resposta de retirada do medicamento deve ser clinicamente plausível. O evento deve ser farmacologicamente ou fenomenologicamente definido utilizando um procedimento de reintrodução satisfatória, se necessário;

Provável: Um evento clínico, incluindo anormalidades de exames laboratoriais, com um tempo de seqüência razoável da administração do medicamento, com improbabilidade de ser atribuído a doença de base ou por outros medicamentos ou substâncias químicas e que segue uma resposta clinicamente razoável após a retirada. A informação de reintrodução não é necessária para completar esta definição; 
Possível: Um evento clínico, incluindo anormalidades de exames laboratoriais, com um tempo de sequiência razoável da administração do medicamento, mas que poderia também ser explicado pela doença de base ou por outros medicamentos ou substâncias químicas. A informação sobre a retirada do medicamento pode ser ausente ou não ser claramente conhecida;

Improvável: Um evento clínico, incluindo anormalidades de exames laboratoriais, com uma relação de tempo com a administração do medicamento que determina uma improvável relação causal, e no qual outros medicamentos, substâncias químicas ou doenças subjacentes fornecem explicações plausíveis;

Condicional/Não classificado: Um evento clínico, incluindo anormalidades de exames laboratoriais, relatados como um evento adverso, sobre o qual é essencial mais dados para uma avaliação apropriada ou os dados adicionais estão sob observação;

Não acessível/Não classificável: Um relato sugerindo uma reação adversa que não pode ser julgada porque a informação é insuficiente ou contraditória, e que não pode ser suplementada ou verificada.

Para investigação de queixa técnica as variáveis pesquisadas foram: o mês da notificação, a descrição do desvio de qualidade, o medicamento classificado por grupo farmacológico segundo a classificação anatômico terapêutica (ATC), a forma farmacêutica e a categoria profissional do notificador.

As variáveis consideradas para a tecnovigilância foram: o mês da notificação, o produto, o número de vezes que o fato ocorreu, a área ou setor da ocorrência, a descrição do acontecimento, se causou ou poderia ter causado agravos à saúde, o tipo de agravos, se os produtos são descartáveis, o número de reprocessamento, a validade do produto, a validade 
da esterilização, o cumprimento das recomendações de manutenção do fabricante e o profissional notificador.

O hospital e o fabricante foram identificados por códigos.

Para averiguar o princípio ativo dos medicamentos com nome comercial foram utilizados dados da literatura (PR VADEMECUM 2001/2002, BASILE e ZANINI 1999). 


\section{4 - RESULTADOS E DISCUSSÃO}

\section{1 - Descrição geral das notificações}

O número de notificações recebidos pela ANVISA desde a implantação do sistema estão distribuídos na tabela 1 .

Tabela 1 - Notificações recebidas pela ANVISA, segundo áreas e ano, Brasil, 2001 a 2004.

\begin{tabular}{cccccc}
\hline ÁREAS/ANO & $\mathbf{2 0 0 3}$ & $\mathbf{2 0 0 4}$ & OUTROS * & TOTAL & \% \\
\hline Farmacovigilância & 239 & 811 & 223 & 1273 & 21,6 \\
Tecnovigilância & 749 & 1805 & 1321 & 3875 & 65,6 \\
Investigação de queixa técnica & 44 & 623 & $\mathbf{8 7}$ & 754 & 12,8 \\
\hline TOTAL & $\mathbf{1 0 3 2}$ & $\mathbf{3 2 3 9}$ & $\mathbf{1 6 3 1}$ & $\mathbf{5 9 0 2}$ & $\mathbf{1 0 0 , 0}$ \\
\hline
\end{tabular}

Fonte: SINEPS - Programa de auditoria de notificações. ANVISA, 2005.

Nota *: Notificações recebidas pela ANVISA por fax, e-mail ou outro meio, antes da implantação do sistema e que foram inseridas posteriormente no mesmo.

Observa-se que as notificações para a área de tecnovigilância representaram em média três vezes mais o número de notificações da área de farmacovigilância. $O$ pequeno número da área de investigação, em 2003, se deve ao fato de que, no início, a farmacovigilância recebia todas as notificações relacionadas a medicamentos e, posteriormente, foi criado um campo no sistema de informação, especificamente para queixas técnicas de medicamentos transferindo-as para a área de investigação.

A tabela 2 mostra a distribuição de hospitais sentinelas por Estados da Federação. Os Estados da região sudeste tem o maior número de hospitais sentinelas (48), seguido pela 
região nordeste (20 hospitais), Sul (15 hospitais) e regiões Centro Oeste e Norte com 8 hospitais cada uma.

Tabela 2 - Distribuição dos hospitais sentinelas por Estados da Federação, ANVISA, 2004.

\begin{tabular}{lc}
\hline ESTADOS & Número \\
\hline RORAIMA & 01 \\
AMAZONAS & 01 \\
ACRE & 01 \\
RONDÔNIA & 01 \\
AMAPÁ & 01 \\
PARÁ & 02 \\
TOCANTINS & 01 \\
MATO GROSSO & 01 \\
MATO GROSSO DO SUL & 02 \\
DISTRITO FEDERAL & 03 \\
GOIÁS & 02 \\
PIAUÍ & 01 \\
MARANHÃO & 01 \\
BAHIA & 03 \\
CEARÁ & 05 \\
SERGIPE & 01 \\
ALAGOAS & 01 \\
PERNAMBUCO & 05 \\
PARAÍBA & 02 \\
RIO GRANDE DO NORTE & 01 \\
RIO GRANDE DO SUL & $\mathbf{0 8}$ \\
SANTA CATARINA & $\mathbf{0 2}$ \\
PARANÁ & 05 \\
MINAS GERAIS & 08 \\
ESPÍRITO SANTO & 01 \\
RIO DE JANEIRO & 08 \\
SÃO PAULO & 31 \\
\hline TOTAL & $\mathbf{9 9}$ \\
\hline \multicolumn{1}{c}{ FOnte: ANVISA $2005 \mathrm{~d}$}
\end{tabular}

Fonte: ANVISA, 2005d

Os gráficos 1, 2 e 3 mostram as distribuições das notificações recebidas nas áreas de farmacovigilância, tecnovigilância e queixa técnica, respectivamente, durante o ano de 2004, por Estados da Federação. 
Pode-se observar que a área de tecnovigilância recebeu notificações de mais Estados do que as outras áreas. A farmacovigilância e a área de investigação receberam notificações de 13 Estados, a tecnovigilância de 18 Estados.

$\mathrm{Na}$ área de farmacovigilância os Estados do Sul (RS, SC e PR) responderam por $55 \%$ das notificações, sendo que somente o Rio Grande do Sul participou com $35,6 \%$ das notificações, o Estado de São Paulo respondeu por 13\% das notificações desta área.

No trabalho realizado por DIAS et al (2002) sobre a descrição das notificações de suspeitas de reação adversa a medicamentos recebidas na Unidade de Farmacovigilância da ANVISA, no primeiro semestre de 2002 , mostrou que $57 \%$ das notificações eram proveniente da região sudeste, $18 \%$ da região nordeste, $14 \%$ da região sul, ou seja, estes dados referem-se ao consolidado do início da implantação do Sistema de Notificações, mostrando um maior número de notificações em regiões com maior número de hospitais sentinelas, embora este trabalho também inclua outras notificações além dos sentinelas, mas a maior parte delas é representada por estes hospitais.

Podemos observar, também, que a região sul aumentou consideravelmente o número de notificações enviadas para a ANVISA. É provável que os governos destes Estados ou os gerentes de risco dos hospitais sentinelas tenham feito investimentos em educação continuada com o intuito de estimular as notificações. É necessário um estudo mais detalhado sobre este assunto para melhor compreender a situação descrita. 


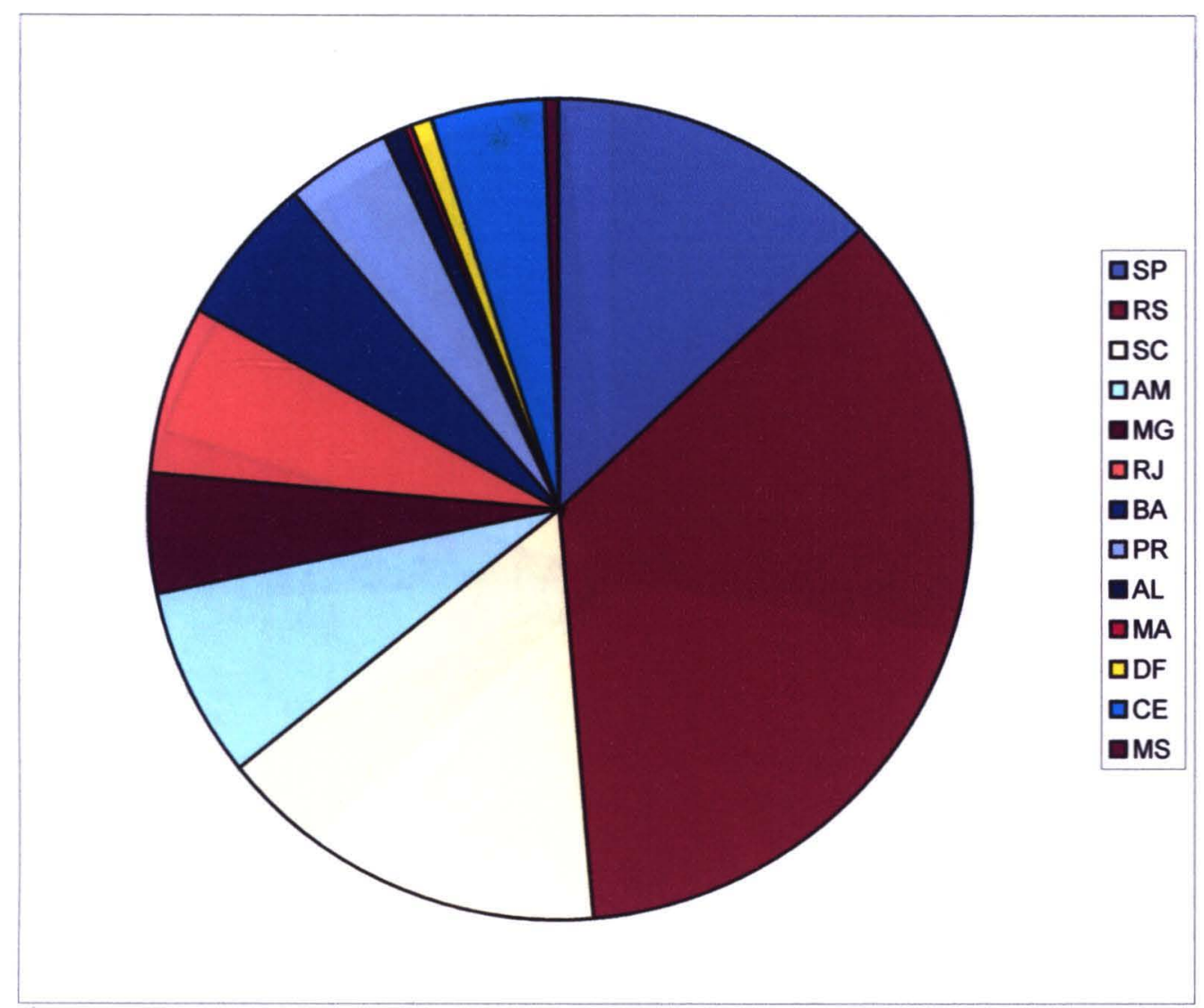

Gráfico 1 - Distribuição das notificações recebidas pela farmacovigilância por Estados da Federação, ANVISA, 2004

Fonte: SINEPS - Programa de auditoria de notificações. ANVISA, 2005.

$\mathrm{Na}$ área de tecnovigilância, o Estado do Rio Grande do Sul foi também o que mais notificou (33\%), seguido por São Paulo (26\%) e Minas Gerais (9\%). Finalmente, para as notificações de queixas técnicas, o Estado de São Paulo respondeu por 39\%, seguido por Rio de Janeiro (14\%) e Minas Gerais (10\%). 


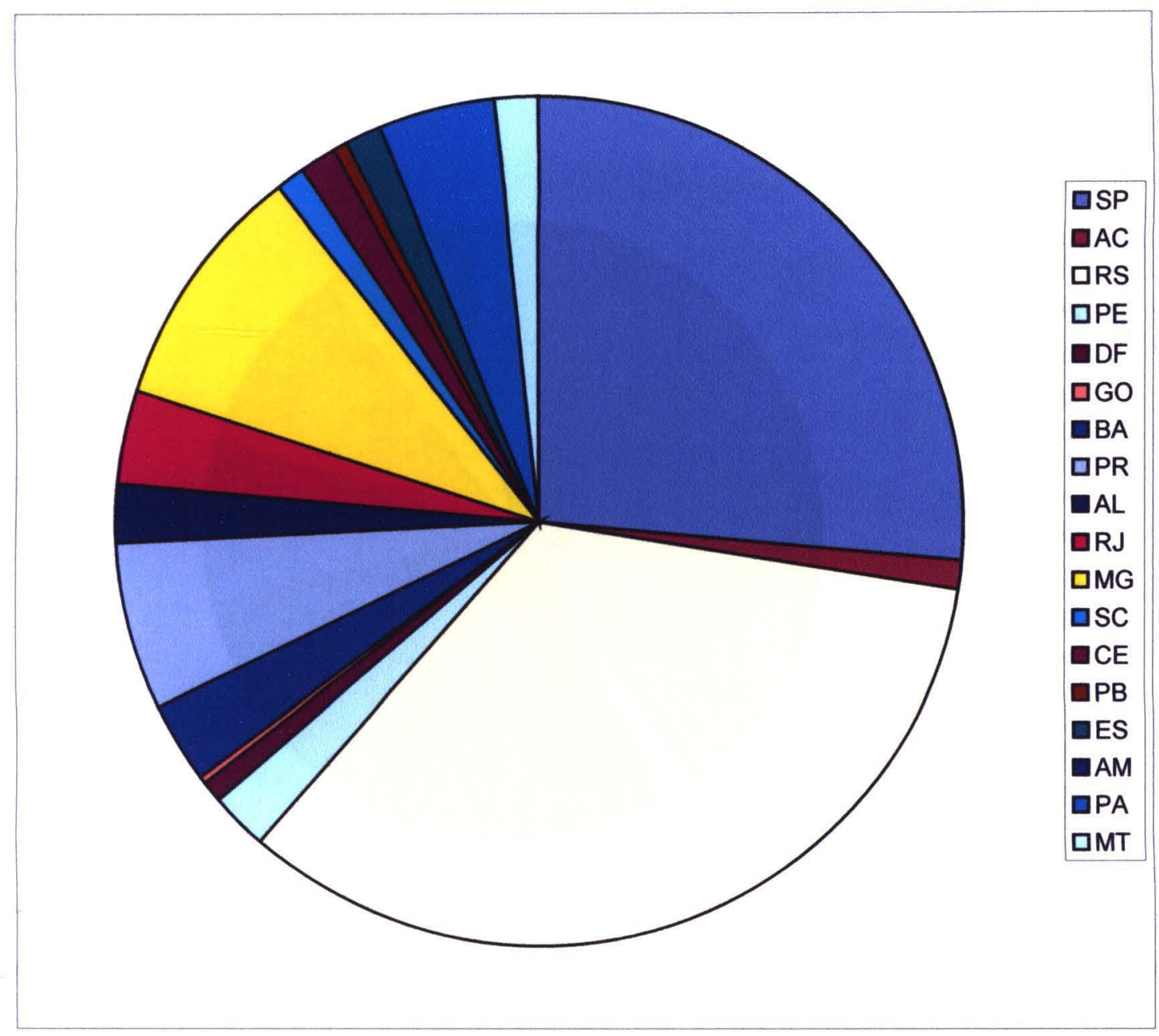

Gráfico. 2 - Distribuição das notificações da tecnovigilância por Estados da Federação, ANVISA, 2004.

Fonte: SINEPS - Programa de auditoria de notificações. ANVISA, 2005. 


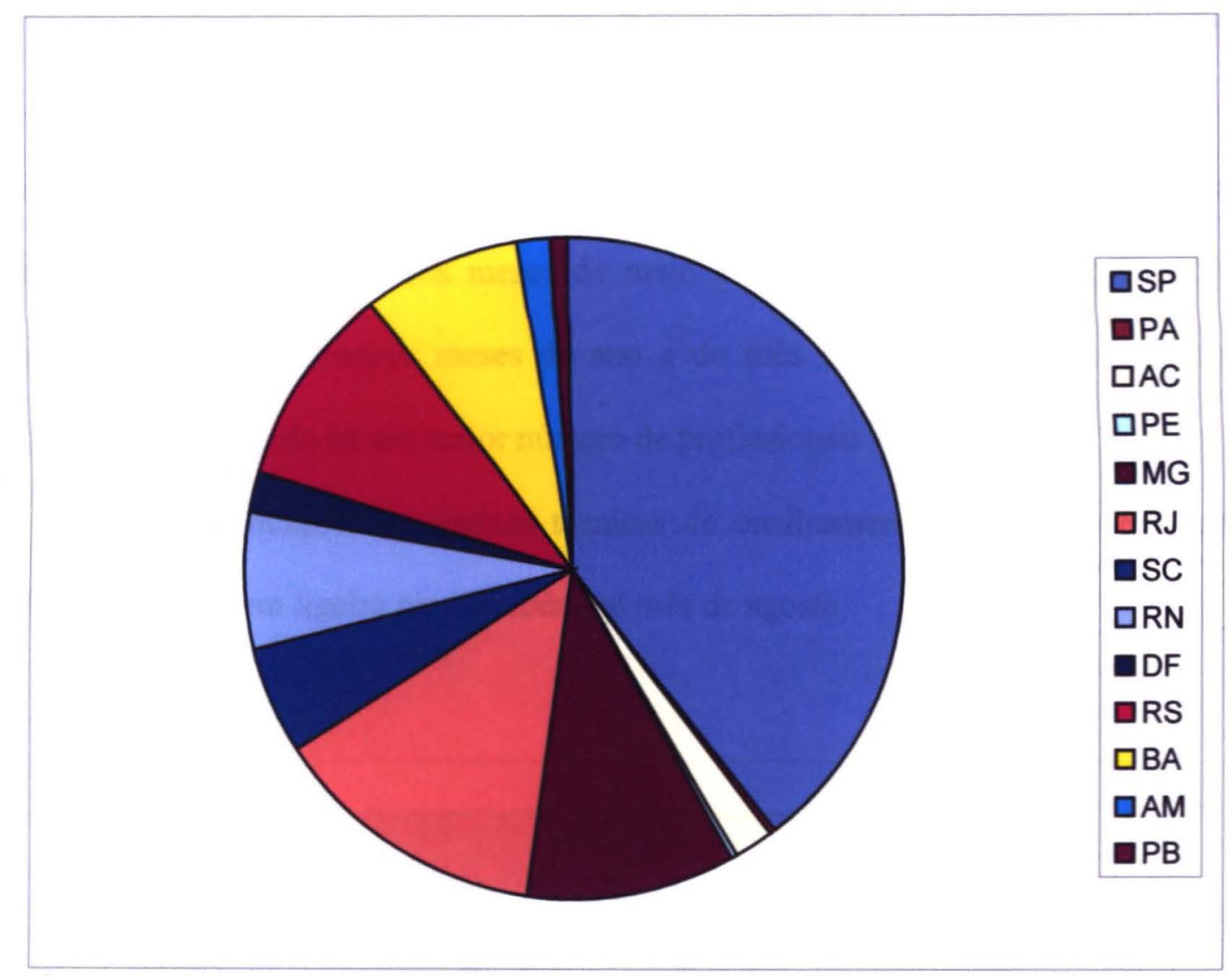

Gráfico 3 - Distribuição das notificações de queixa técnica por Estados da Federação, ANVISA, 2004.

Fonte: SINEPS - Programa de auditoria de notificações. ANVISA, 2005.

O gráfico seguinte mostra a distribuição das notificações recebidas durante os meses de janeiro a dezembro de 2004. A farmacovigilância teve dois picos de notificações: nos meses de agosto e setembro, mantendo-se estável nos outros meses e com boa diminuição das notificações nos meses de janeiro e fevereiro.

$\mathrm{Na}$ área de tecnovigilância o pico de notificação ocorreu nos meses de maio e agosto, mantendo-se estável nos outros meses, mas com maior queda para os meses de janeiro, fevereiro, novembro e dezembro. 
A queda no número de notificações nos meses de janeiro, fevereiro, novembro e dezembro poderiam ser justificadas em função de muitos profissionais, provavelmente, estarem no período de férias. Pode ser, também, que os picos relacionados ao aumento do número de notificações, dos meses de maio e agosto, ocorram devido ao acúmulo de notificações dos primeiros meses do ano e do mês de julho, e que posteriormente são investigadas quando há um maior número de profissionais trabalhando.

As notificações de queixas técnicas de medicamentos se mantiveram estáveis ao longo do ano com ligeiro pico também no mês de agosto.

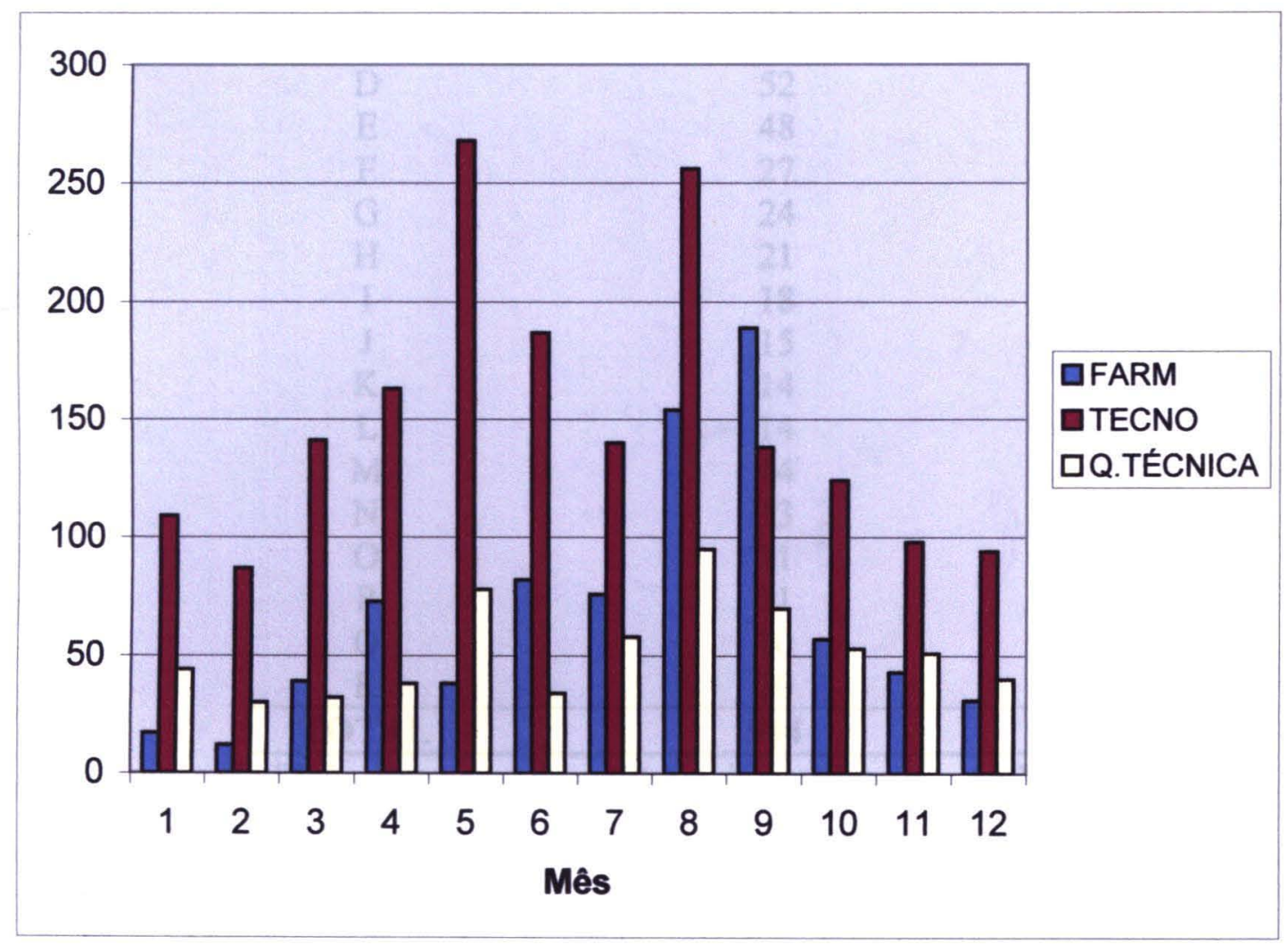

Gráfico 4 - Notificações recebidas das três áreas segundo mês do ano, ANVISA, 2004. Fonte: SINEPS - Programa de auditoria de notificações. ANVISA, 2005. 
A tabela 3 mostra as empresas com maior número de queixas técnicas na área de investigação.

As empresas que tiveram 10 ou mais notificações estão representadas na tabela abaixo (por códigos). Estas 18 empresas representam $66,3 \%$ de todas as queixas técnicas.

Tabela 3 - Numero de notificações de queixa técnica por empresas (descritas por códigos), ANVISA, 2005.

\begin{tabular}{cc}
\hline EMPRESAS & NÚMERO DE NOTIFICAÇÕES \\
\hline A & 83 \\
B & 60 \\
C & 59 \\
D & 52 \\
E & 48 \\
F & 27 \\
G & 24 \\
H & 21 \\
I & 18 \\
J & 15 \\
K & 14 \\
L & 14 \\
M & 14 \\
N & 13 \\
O & 11 \\
P & 11 \\
Q & 10 \\
R & 10 \\
\hline TOTAL & $\mathbf{5 0 4}$ \\
\hline
\end{tabular}

Fonte: SINEPS - Programa de auditoria de notificações. ANVISA, 2005.

Os problemas relacionados à queixa técnica de medicamentos nem sempre se referem às condições de produção dos medicamentos. Podem estar relacionadas a problemas de transporte, armazenamento ou utilização inadequada. De qualquer maneira a 
mpresa produtora é responsável no sentido de se preocupar como seus produtos estão endo disponibilizados.

Se as queixas técnicas de medicamentos estiverem relacionadas com a produção dos nesmos, a ANVISA, além das medidas sanitárias necessárias, pode fazer um levantamento e a concentração de empresas que tiveram maiores números de notificações estão oncentradas em poucos Estados ou estão espalhadas pelo País. Se estiverem concentradas m determinado Estado, pode-se discutir com as equipes de vigilância daquele Estado, stratégias para diminuir esse número.

A tabela 4 mostra as vinte e uma empresas que tiveram mais que 25 notificações de eus produtos na área de tecnovigilância, representando $54 \%$ do total de notificações da rea. 
Tabela 4 - Número de notificações de tecnovigilância por fabricante (descrito por códigos). ANVISA, 2005.

\begin{tabular}{cc}
\hline EMPRESAS & NÚMERO DE NOTIFICAÇÕES \\
\hline A & 333 \\
B & 285 \\
C & 238 \\
D & 161 \\
E & 130 \\
F & 126 \\
G & 122 \\
H & 97 \\
I & 77 \\
J & 71 \\
K & 67 \\
L & 55 \\
M & 51 \\
N & 50 \\
O & 44 \\
P & 41 \\
Q & 34 \\
R & 30 \\
S & 29 \\
T & 28 \\
U & 27 \\
\hline TOTAL & $\mathbf{2 0 9 6}$ \\
\hline
\end{tabular}

Fonte: SINEPS - Programa de auditoria de notificações. ANVISA, 2005.

Para a vigilância sanitária esse dado é importante, pois deve-se fazer uma avaliação de que produtos destas empresas estão com problemas, se estes produtos possuem registro, qual a categoria de risco dos produtos, o número de notificações está concentrado em um único produto ou em vários, quanto a empresa produziu daquele produto objeto da notificação, situação da empresa quanto ao cumprimento de Boas Práticas de Fabricação. Estas questões e outras podem demandar uma inspeção investigativa nos pontos críticos relacionados ao problema notificado, como por exemplo, o controle de aquisição de matéria prima, controle de projetos, sistema de qualidade da empresa, controle de documentos e 
egistros, rastreabilidade do produto, controle de processo e produção, técnicas de statística.

1.2 - Amostragem: setembro a dezembro 2004.

Tabela 5 - Notificações recebidas pelo SINEPS de todos os Estados da Federação, egundo áreas, no período de setembro a dezembro de 2004.

\begin{tabular}{ccc}
\hline ÁREAS & NÚMERO & PORCENTAGEM \\
\hline Farmacovigilância & 320 & 33,5 \\
Tecnovigilância & 422 & 44,1 \\
Investigação & 214 & 22,4 \\
\hline TOTAL & $\mathbf{9 5 6}$ & $\mathbf{1 0 0 , 0}$ \\
\hline
\end{tabular}

Fonte: SINEPS - Programa de auditoria de notificações. ANVISA, 2005.

O gráfico 5 ilustra o número de notificações recebidas através do SINEPS para a rea de tecnovigilância, segundo Estados da Federação no período compreendido da mostragem.

O Estado de São Paulo foi o que mais notificou neste período (setembro a dezembro e 2004) para a área de tecnovigilância, representando 35\% das notificações, seguido pelo stado do Rio Grande do Sul com 18\% e Minas Gerais com 9\%. Se compararmos com o 10 todo de 2004 (gráfico 2) notamos que houve uma inversão, pois considerando o ano Ido o Estado do Rio Grande do Sul (33\%) foi o que mais notificou, seguido pelo Estado de ão Paulo (26\%) e no período da amostragem é o inverso. Muitas variáveis podem estar ıvolvidas nesta oscilação como, por exemplo, aumento do número de profissionais 
notificadores, no período, ou alguma ação local desencadeada pelo gerente de risco que pudesse estimular a notificação.
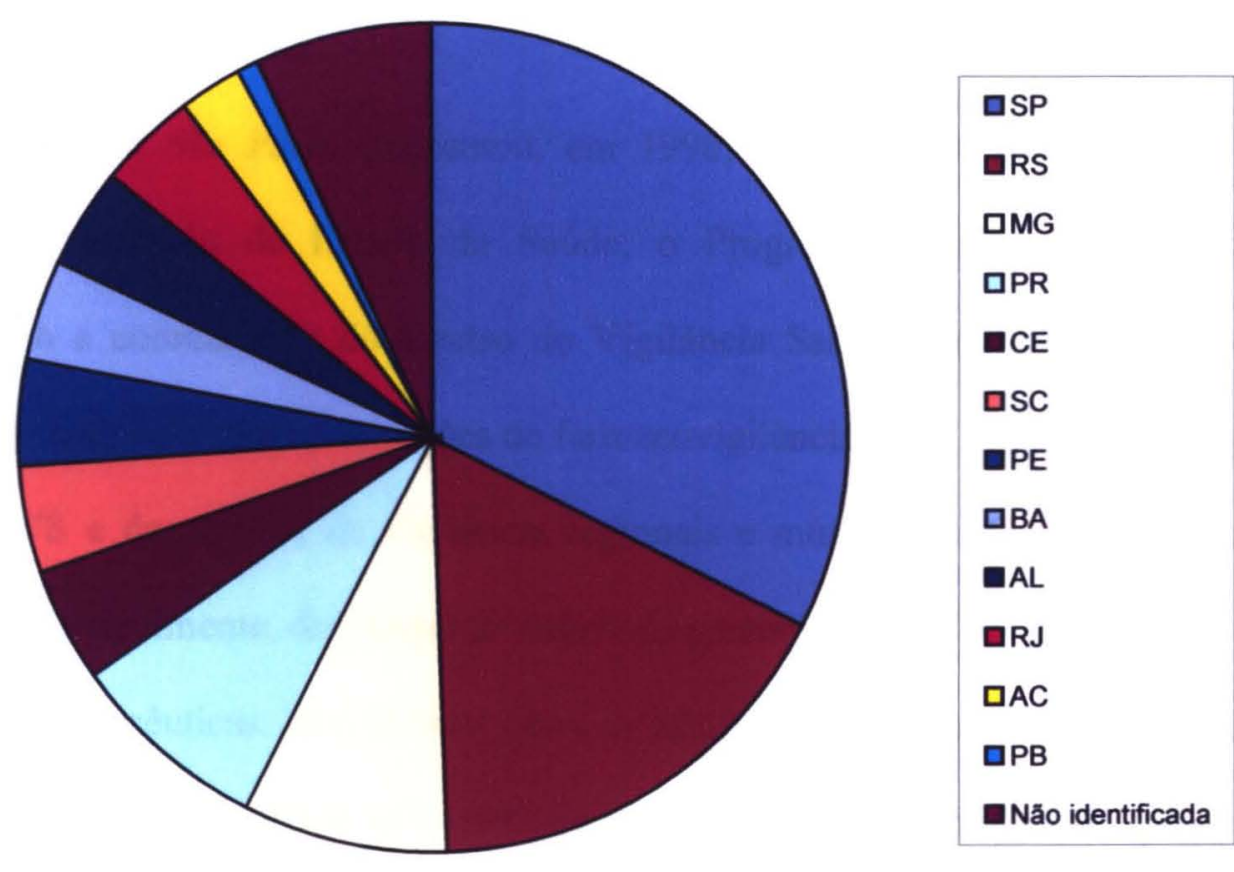

Gráfico. 5 - Notificações enviadas à ANVISA (SINEPS) para área de tecnovigilância, por estados da Federação, 09/2004 a 12/2004

Fonte: SINEPS - Programa de auditoria de notificações. ANVISA, 2005.

O gráfico 6 ilustra as notificações recebidas pelo SINEPS para área de farmacovigilância segundo Estados da Federação.

Nesta área, o Estado que mais notificou foi Rio Grande do Sul representando $50 \%$ das notificações, seguido por São Paulo com 12,5\% e Santa Catarina com 11\%. Considerando todo o ano de 2004, podemos observar que o Estado do Rio Grande do Sul 
respondeu por $35,6 \%$ das notificações enviadas e neste período de amostragem elas representaram $50 \%$ das notificações enviadas à ANVISA; para o Estado de São Paulo houve uma queda de $0,5 \%$ das notificações no período da amostragem comparando-se com o ano inteiro. É possível que tenha ocorrido algum processo educativo no Estado do Rio Grande do Sul, no sentido de incrementar as notificações ou alguns Estados diminuíram sensivelmente suas notificações.

O Estado de São Paulo implantou, em 1998, por meio da resolução SS 17 de 13/04/98, do Secretário de Estado da Saúde, o Programa Estadual de Redução de Iatrogenias sob a coordenação do Centro de Vigilância Sanitária (CVS). Esta resolução aponta para o desenvolvimento das ações de farmacovigilância e sua incorporação à prática regular do CVS e dos órgãos de vigilância regionais e municipais. O programa recebeu notificações, principalmente, dos hospitais estaduais gerenciados por organizações sociais e das empresas farmacêuticas. Nos últimos anos, as notificações das empresas farmacêuticas que operam no Estado vêm crescendo, enquanto que o número de notificações proveniente dos estabelecimentos de saúde estabilizou-se no patamar registrado no último trimestre de 2004 (SILVA E MENEZES, 2005).

Embora os hospitais estaduais gerenciados por organizações sociais não coincidam com os hospitais sentinelas, é fundamental estabeler uma estratégia diferenciada para atingir esse segmento e promover capacitações freqüentes, bem como o retorno das informações aos notificadores.

É importante salientar a pequena participação do Estado do Ceará frente ao número de notificações enviadas em relação aos outros Estados. Naquele Estado há 5 hospitais sentinelas como no Estado de Rio Grande do Sul, entretanto, a desproporção em relação ao 
número de notificações enviadas pode ser visualizada no gráfico. O Estado do Ceará foi o pioneiro, no Brasil, na implantação de um projeto de farmacovigilância coordenado pelo Grupo de Prevenção ao Uso Indevido de Medicamentos (GPUIM), da Universidade Federal do Ceará, e que envolvia alguns hospitais da Secretaria de Saúde do Estado. Muitos fatores podem influenciar na motivação dos profissionais de saúde quanto à notificação de reações adversas, dentre eles destaca-se como importante o retorno das informações ao notificador e a efetividade e eficácia das ações de vigilância frente ao problema encontrado.

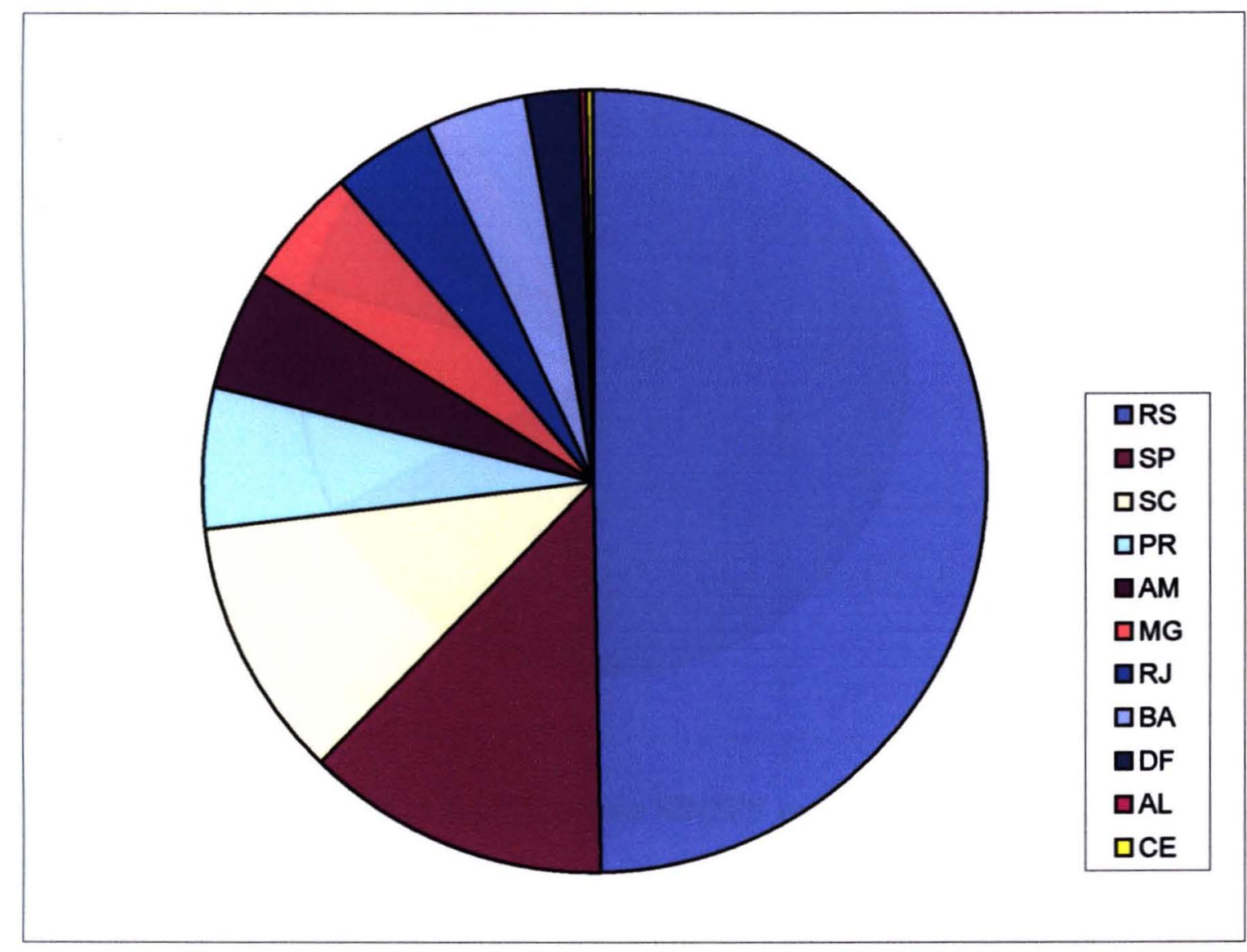

Gráfico 6 - Reações adversas a medicamentos recebidas pelo SINEPS por Estados da Federação, 09/2004 a 12/2004. 
Fonte: SINEPS - Programa de auditoria de notificações. ANVISA, 2005.

O gráfico 7, mostra as queixas técnicas recebidas por Estados da Federação no período de amostragem.

O Estado de São Paulo contribuiu com $49 \%$ das notificações desta área, seguido por Rio de Janeiro com $18 \%$ e Bahia com $12 \%$. Considerando todo o ano de 2004, o Estado de São Paulo respondeu por $39 \%$ das notificações, sendo que, no período de amostragem correspondeu a $49 \%$ das mesmas em relação aos outros Estados da Federação.

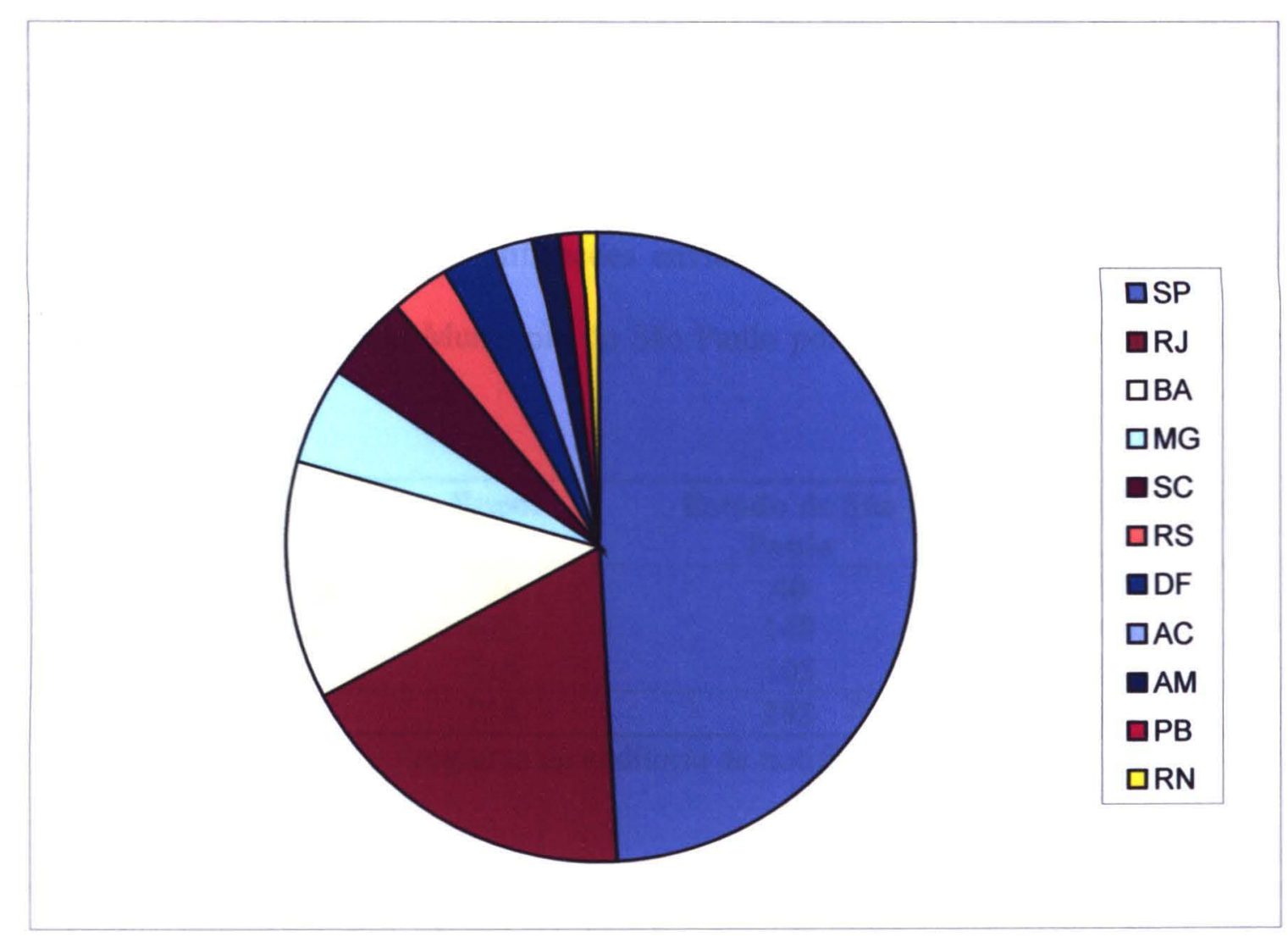

Gráfico 7 - Queixas técnicas recebidas pelo SINEPS por Estados da Federação, 09/2004 a 12/2004.

Fonte: SINEPS - Programa de auditoria de notificações. ANVISA, 2005. 


\section{3 - Município de São Paulo}

No município de São Paulo tem-se vinte (20) hospitais sentinelas, sendo dois (2) privados, três (3) filantrópicos e 15 hospitais públicos. São hospitais de médio e grande porte, sendo quatro (4) hospitais são especializados e cinco (5) ligados à Universidade.

A tabela 6 mostra o número de notificações do Estado e do Município de São Paulo segundo as áreas. Pode-se notar, que na área de farmacovigilância e de investigação, o número de notificações do município, representou um pouco mais da metade das notificações do Estado e na área de tecnovigilância as notificações do município representaram $71,6 \%$ do total enviado pelo Estado.

Tabela 6 - Número de notificações enviadas por todos os Estados da Federação (Brasil), pelo Estado e pelo Município de São Paulo por áreas, no período de setembro a dezembro de 2004.

\begin{tabular}{cccc}
\hline ÁREAS & Brasil & $\begin{array}{c}\text { Estado de São } \\
\text { Paulo }\end{array}$ & $\begin{array}{c}\text { Município de São } \\
\text { Paulo }\end{array}$ \\
\hline Farmacovigilância & 320 & 40 & 21 \\
Tecnovigilância & 422 & 148 & 106 \\
Investigação & 214 & 105 & 56 \\
\hline TOTAL & $\mathbf{9 5 6}$ & $\mathbf{2 9 3}$ & $\mathbf{1 8 3}$ \\
\hline
\end{tabular}

Fonte: SINEPS - Programa de auditoria de notificações. ANVISA, 2005.

\subsection{1 - Farmacovigilância}

Das 32 notificações apontadas pelo SINEPS, 25 foram encontradas e destas, 4 estavam repetidas e foram excluídas. Observou-se que o sistema não tem um bloqueio para notificações idênticas, o que constitui um problema porque os dados gerais podem se 
distanciar da realidade, ou seja, super estima-los. Com relação à não localização das fichas de notificação é provável que o hospital tenha feito a notificação fora do sistema, a agência contabilizou, mas a ficha não estava disponível on-line. Estes problemas somente puderam ser observados quando se trabalhou com as fichas de notificação na amostragem do município.

De vinte hospitais sentinelas no município de São Paulo, apenas 4 (20\%) enviaram notificação à ANVISA sendo 2 filantrópicos e 2 públicos, todos eles estavam desde o início do projeto sentinela. Destes quatro, apenas um foi responsável por quase $50 \%$ das notificações, conforme mostra a tabela abaixo:

Tabela 7 - Número e porcentagem de notificações da área de farmacovigilância por hospitais (representados por códigos), no município de São Paulo, no período de setembro a dezembro de 2004.

\begin{tabular}{ccc}
\hline HOSPITAL & NÚMERO & $\%$ \\
\hline A & 10 & $47,6 \%$ \\
B & 06 & $28,6 \%$ \\
E & 01 & $4,8 \%$ \\
H & 04 & $19,0 \%$ \\
\hline TOTAL & $\mathbf{2 1}$ & $\mathbf{1 0 0 , 0}$
\end{tabular}

Fonte: SINEPS - Programa de auditoria de notificações. ANVISA, 2005.

Muitos hospitais, no Município de São Paulo, ainda não conseguiram implementar as ações no âmbito da gerência de risco que envolve a sensibilização e capacitação dos profissionais de saúde do hospital para adquirirem a cultura da notificação, a divulgação das ações desta gerência de risco no hospital, a reunião de todas as notificações, análise, 
estabelecimento da causalidade, o envio das notificações para a ANVISA, a proposição de medidas corretivas, dentre outras. Além disso, outros fatores como os relacionados à mudança do gerente de risco e excesso de trabalho dos mesmos acabam dificultando a continuidade e dedicação a esta atividade.

As tabelas subseqüentes mostram as freqüências de notificações por mês e segundo profissional notificador:

Tabela 8 - Número e porcentagem de notificações da área de farmacovigilância, no município de São Paulo segundo mês, no período de setembro a dezembro de 2004.

\begin{tabular}{ccc}
\hline MÊS & NÚMERO & $\%$ \\
\hline SETEMBRO & 13 & 61,9 \\
OUTUBRO & 03 & 14,3 \\
DEZEMBRO & 05 & 23,8 \\
\hline TOTAL & $\mathbf{2 1}$ & $\mathbf{1 0 0 , 0}$
\end{tabular}

Fonte: SINEPS - Programa de auditoria de notificações. ANVISA, 2005.

Observou-se que no mês novembro não consta nenhuma notificação e existe uma variação nos outros meses. O maior número de notificações no mês de setembro coincide com a apresentação do gráfico 4 . É provável que esteja relacionado à disponibilidade maior de recursos humanos neste período do que nos meses, tradicionalmente relacionados às férias. Seria importante realizar estudos mais detalhados para verificar essas oscilações. 
Tabela 9 - Número e porcentagem de notificações da área de farmacovigilância, no município de São Paulo segundo profissional notificador, no período de setembro a dezembro de 2004.

\begin{tabular}{ccc}
\hline PROFISSIONAL & NÚMERO & $\%$ \\
\hline ENFERMEIRO & 02 & 9,5 \\
FARMACÊUTICO & 07 & 33,3 \\
MÉDICO & 12 & 57,2 \\
\hline TOTAL & $\mathbf{2 1}$ & $\mathbf{1 0 0 , 0}$
\end{tabular}

Fonte: SINEPS - Programa de auditoria de notificações. ANVISA, 2005.

Com relação ao profissional notificador, os médicos foram os que mais notificaram. È importante salientar que os gerentes de risco de três dos quatro hospitais notificadores desta área eram médicos e um enfermeiro. Ressalta-se a notificação do profissional farmacêutico que deve estar atuando nas clínicas dos hospitais para ter conseguido coletar as informações sobre as reações adversas.

Das vinte e uma notificações apenas uma tratava-se de seguimento de caso, ou seja, era uma segunda notificação referente ao mesmo caso, apenas para complementar as informações enviadas anteriormente.

Das notificações enviadas, $66,7 \%$ eram do sexo feminino e quanto à faixa etária $57 \%$ estavam entre 35 e 64 anos e $28,5 \%$ acima de 65 anos. O trabalho realizado por SILVA e MENEZES (2005) também mostra a tendência das reações adversas ocorrerem com maior freqüência no sexo feminino e em indivíduos acima de 30 anos. 
Quanto aos grupos farmacológicos mais freqüentes, o grupo de agentes antineoplásicos e imunomoduladores, representou $28,5 \%$ das notificações, o grupo de antimicrobianos de uso sistêmico, $23,8 \%$ e o grupo dos agentes do sangue $14,2 \%$. Houve notificação dos seguintes grupos: agentes do sangue, sistema cardiovascular, antimicrobianos de uso sistêmico, antineoplásicos e imunomoduladores, sistema músculo esquelético, sistema nervoso e sistema respiratório. A freqüente notificação do grupo de antineoplásicos se justifica pelo fato de um dos hospitais notificadores ser especializado no tratamento de câncer.

No trabalho de MORALESD et al (2002), que avaliou as notificações de reações adversas recebidas pelo Programa Nacional de Farmacovigilância do Instituto de Saúde Pública do Chile (1797 notificações), encontrou-se uma prevalência grande para o grupo de antimicrobianos, com $31 \%$ das notificações, seguido pelo grupo do Sistema Nervoso.

Quanto à gravidade, encontrou-se que 60\% das reações adversas foram consideradas moderadas, $20 \%$ graves e $20 \%$ leves. As reações adversas leves não deveriam estar sendo notificadas, pois normalmente não demandam ações da vigilância.

Quanto à causalidade, 70\% foram consideradas prováveis, 25\% definidas ou certas e havia uma notificação sem classificação $(4,7 \%)$. A relação temporal foi dada como plausível em 19 notificações, não plausível em uma e uma notificação sem resposta. 0 estudo de CARLINI e NAPPO (2003) analisou 219 notificações de suspeitas de reações adversas produzidas por medicamentos psicoativos, encontrando uma proporção de $10,9 \%$ de causalidade considerada definida e $61 \%$ classificadas como prováveis, utilizando o algoritmo de Karch \& Lasagna. 
No estudo de GROHMANN et al (2004), realizado na Alemanha, avaliou-se as reações adversas desenvolvidas em pacientes internados em 2 hospitais psiquiátricos, entre 1979 e 1989, mostrando proporções semelhantes ao estudo de CARLINI e NAPPO (2003) quanto à causalidade: dos $60,7 \%$ pacientes que experimentaram pelo menos uma reação adversa, a causalidade foi considerada definida e provável e 1,4\% das RAM foram consideradas graves.

DEVI et al (2004) realizaram um estudo em um hospital da Índia sobre medicamentos que induziram reações adversas do trato gastrintestinal alto para verificar, também, a categoria de causalidade segundo a OMS. Encontraram que dos 101 casos analisados, $8(7,9 \%)$ foram consideradas definidas, $87(86,1 \%)$ prováveis e $6(5,9 \%)$ possiveis. Os medicamentos relacionados a esta RAM foram, principalmente, os antiinflamatórios não esteroidais.

No estudo de TEMPLE et al (2004), realizado nos Estados Unidos, foram coletadas informações do programa de vigilância hospitalar, no período de janeiro de 1994 a dezembro de 1999, sobre as reações adversas em pacientes pediátricos. Encontraram neste período a notificação de 565 reações adversas. Os principais medicamentos envolvidos com as RAM foram os opióides, os anticonvulsivantes e os antiinfecciosos. Classificaram a causalidade como definida em $44,1 \%$ dos casos, como provável em $49,9 \%$ dos casos e como possível em $6 \%$ dos casos.

Um outro estudo relacionado à causalidade é o de LIU et al (2001), realizado no Canadá, no período de 1990 a 1994. Eles fizeram uma revisão das notificações de reações adversas fatais. Encontraram 97 casos de RAM relacionados à morte, destes $60 \%$ dos casos eram de pessoas acima de 65 anos de idade. Os medicamentos suspeitos foram os que 
atuam no sistema músculo-esquelético, agentes do sangue e os que atuam no sistema nervoso central. Referente à causalidade consideraram $13 \%$ dos casos como prováveis, $86 \%$ como possíveis e $1 \%$ como improvável.

Quanto à questão de evolução $81 \%$ se recuperaram e em $61,9 \%$ dos casos houve necessidade de tratamento da reação adversa; verificou-se uma notificação em que houve relato de seqüela e não havia nenhuma informação sobre óbito.

\subsection{2 - Investigação de queixas técnicas de medicamentos}

$\mathrm{O}$ número de hospitais que notificaram para esta área foi igual a sete, sendo 02 filantrópicos e 5 públicos, três (3) destes ligados à universidade. Um deles contribuiu com $37,5 \%$ das notificações e outro com $28,6 \%$ das notificações.

A distribuição das notificações, por mês, foi de $50 \%$ para o mês de setembro, $30,4 \%$ para o mês de outubro, $1,8 \%$ para o mês de novembro e $17,8 \%$ para o mês de dezembro. De forma semelhante à farmacovigilância em que não houve nenhuma notificação no mês de novembro, na área de investigação de queixa técnica de medicamentos, também neste mês ocorre uma diminuição, que pode estar ligada a recurso humano disponível neste período para esta atividade, bem como ter ocorrido um problema no sistema impedindo temporariamente a notificação.

Os profissionais que mais notificaram queixas técnicas foram os médicos com $41,1 \%$, seguido pelos enfermeiros com $39,3 \%$ e farmacêuticos com $14,3 \%$. O trabalho de LACERDA et al (2002) analisou as queixas técnicas recebidas pela Unidade de Farmacovigilância da ANVISA, entre janeiro e setembro de 2002. Dos 152 casos notificados, $52 \%$ foram registrados por farmacêuticos e $25 \%$ por médicos. As queixas mais 
comuns foram: ineficácia terapêutica (32\%), alterações fisico-químicas (26\%) e relativas à embalagem (25\%).

Os grupos farmacológicos que foram mais notificados são apresentados na tabela 10.

Tabela 10 - Número e porcentagem de notificações de queixas técnicas de medicamentos, no município de São Paulo por grupo, segundo a classificação anátomoterapêutica-química (ATC), no período de setembro a dezembro de 2004.

\begin{tabular}{ccc}
\hline GRUPO & NÚMERO & $\%$ \\
\hline Trato alimentar e metabolismo & 06 & 10,8 \\
Agentes do sangue & 14 & 25,0 \\
Sistema Cardiovascular & 10 & 17,8 \\
Antiinfecciosos para uso sistêmico & 07 & 12,5 \\
Antineoplásicos e imunomoduladores & 07 & 12,5 \\
Sistema músculo esquelético & 01 & 1,8 \\
Sistema nervoso & 10 & 17,8 \\
Orgãos sensoriais & 01 & 1,8 \\
\hline TOTAL & $\mathbf{5 6}$ & $\mathbf{1 0 0 , 0}$ \\
\hline
\end{tabular}

Fonte: SINEPS - Programa de auditoria de notificações. ANVISA, 2005.

Com relação à forma farmacêutica, $85,7 \%$ eram queixas de produtos injetáveis, $12,5 \%$ comprimidos e $1,8 \%$ solução. Isto traz uma grande preocupação, pois os produtos injetáveis são estéreis, portanto, com especificações mais rígidas no processo produtivo.

O trabalho de GOMES et al (2002) sobre a vigilância da qualidade de medicamentos, apresentaram os dados relativos ao recebimento e apuração de denúncias com suspeita de irregularidades recebidas pela ANVISA, no período de janeiro a setembro de 2002 e concluíram que das 618 denúncias (analisaram 258 delas), 35\% estavam relacionadas a fármacos na forma sólida e $28 \%$ injetáveis. As principais queixas relacionavam possíveis desvios de qualidade $(13,9 \%)$ e falhas terapêuticas $(12,8 \%)$, 
seguidas por suspeita de alteração na embalagem e rotulagem (11,3\%). Foram identificados três medicamentos falsificados. Para $24 \%$ das suspeitas, não foram encontrados indícios de irregularidades e quatorze lotes de medicamentos tiveram sua comercialização suspensa cautelar ou definitivamente.

As principais queixas estavam relacionadas a problemas com a rotulagem do produto, presença de corpo estranho, vazamento, ausência de conteúdo e falta de eficácia.

Em outro trabalho GOMES et al (2002a) apresentaram os dados relativos ao recebimento e apuração de denúncias envolvendo ineficácia terapêutica, de janeiro a setembro de 2002, recebidos pela gerência de investigação da ANVISA. Verificaram que os antimicrobianos e os fármacos psicoativos foram os que apresentaram o maior número de relatos de falha terapêtica com $22,8 \%$ e $26,3 \%$ respectivamente. Em $38 \%$ dos casos apurados não foram encontrados indícios de irregularidade com o medicamento; $17,7 \%$ relacionavam à utilização inadequada e condições de armazenamento irregulares.

Isto mostra a importância de se manter as condições adequadas em toda a cadeia do medicamento, ou seja, no transporte, armazenamento, utilização do medicamento, dentre outros.

Estiveram envolvidos nestas notificações 22 fabricantes diferentes, sendo que àquele com maior número recebeu 10 queixas.

MATTA et al (2002) realizaram um trabalho sobre a avaliação do parque industrial farmacêutico da classe de antibióticos do Estado do Rio de Janeiro, entre 2000 e 2001. Avaliaram quinze indústrias e mostraram que apenas $46 \%$ destas atendiam às Boas Práticas de Fabricação. Os principais problemas estavam relacionados à qualificação dos 
fornecedores de matérias primas, controle de qualidade das mesmas e validação de processos, podendo comprometer a qualidade do medicamento.

A investigação de queixas técnicas relacionadas a medicamentos envolve várias etapas, dependendo do problema relatado a investigação pode ser direcionada para avaliar pontos críticos como: situação de registro do produto, situação legal da empresa, condições de transporte e armazenamento do produto, condições de utilização dos produtos, por exemplo, diluição de um produto farmacêutico com diluente não especificado pela indústria pode causar vários problemas, inclusive comprometer a eficácia do mesmo, ou inspeção de Boas Práticas de Fabricação na indústria detentora do registro do medicamento notificado.

\subsection{3 - Tecnovigilância}

$\mathrm{Na}$ área de tecnovigilância oito hospitais notificaram. A distribuição mensal ocorreu da seguinte forma: $42,5 \%$ no mês de setembro, $29,2 \%$ no mês de outubro, $16,0 \%$ no mês de novembro e $12,3 \%$ no mês de dezembro. Os principais notificadores foram os enfermeiros que contribuíram com $83,9 \%$ das notificações e os médicos com $13,2 \%$ das mesmas.

Os enfermeiros são profissionais que tradicionalmente gerenciam estes produtos nos hospitais e, portanto, estão também mais familiarizados com a utilização dos mesmos, assim como para notificação de reações adversa a vacinas é um profissional que notifica com freqüência (RANGANATHAN 2003).

Estiveram envolvidas nas notificações 43 empresas, sendo que a maior parte dos produtos estava enquadrada na categoria II de risco. Três empresas tinham dez queixas e o restante abaixo de oito. 
Com relação à área onde ocorreu o evento não havia informação em nenhuma notificação. Muitos produtos médicos podem não ter risco, dependendo de onde ocorram. Por exemplo, informação errada no conteúdo de gaze relacionada à quantidade; se este problema ocorrer em centro cirúrgico é muito mais grave do que se ocorrer em uma clínica, como foi relatado em várias notificações. Desta forma é importante informar o local de ocorrência do evento.

Com relação ao número de vezes que ocorreu o evento com determinado produto, os relatos indicam que $50,5 \%$ ocorreu mais de 15 vezes. A maioria respondeu que o evento não causou agravo $(89,6 \%)$, mas que poderia causar $(52,8 \%)$. Os principais agravos relacionados foram a contaminação do profissional, do ambiente, perda de medicamento, realização de um mesmo procedimento no paciente mais de uma vez, dentre outros.

Com relação às questões: se o produto era descartável, se as recomendações do fabricante foram seguidas, se estava na validade da esterilização, se estava na validade de fabricação e quantas vezes foram usados antes do incidente, não foram respondidas em grande parte, apesar de que alguns destes itens não se aplicarem a determinados produtos.

Diante destes dados, das três áreas, observou-se uma sub-notificação, especialmente, na área de farmacovigilância, não só em relação ao número de hospitais que notificam como também em relação ao pequeno número de notificações daqueles que notificaram. O Brasil por ser o maior mercado farmacêutico da América Latina juntamente, com o México, deveria estar notificando muito mais.

Quando se utiliza o método de notificação espontânea, a sub-notificação é comum, vários trabalhos relatam o problema (BACKSTROM et al 2004; CASTEL et al 2003; MITTMANN et al 2004; TISONOVÁ et al 2004). 
A avaliação do risco deve sempre nortear as notificações com produtos. As deficiências da avaliação de risco são apontadas em várias agências regulatórias (CERTs 2003), pois é a partir dessa avaliação é que as decisões irão ser tomadas.

Para uma boa avaliação do risco da utilização de determinado produto é imprescindivel que as notificações estejam completas e com qualidade de informação.

A preocupação com a notificação e com a qualidade das mesmas é relatada no estudo de SCHACK (2004) que defende o gerenciamento da qualidade das notificações, como ferramenta importante, principalmente na área de farmacovigilância. Esta avaliação pode detectar inclusive notificações de eventos adversos relacionados ao uso inadequado de medicamentos (LIVRY et al 2003) e subsidiar a agência reguladora destes produtos para a tomada de decisões (McEWEN 2004; MOSELEY 2004; PUIJENBROEK 2001; TSINTIS \& MACHE 2004).

Para apoiar as atividades da farmacovigilância como, por exemplo, investigar a relação causal de uma reação adversa com o medicamento, obter informações sobre reações adversas descritas e atualizadas, informação sobre o registro do produto, informações sobre recolhimento de produtos no mundo e outros, é importante ter o apoio de um centro de informações sobre medicamentos.

Os Centros de Informações sobre Medicamentos caracterizam-se por fornecer informação farmacológica, terapêutica e toxicológica atualizada, objetiva, oportuna e isenta de pressões políticas, econômicas e comerciais (VIDOTTI, 1997).

Com o aumento no número de medicamentos disponíveis no mercado e sua complexidade, a literatura específica sobre este tema também cresceu, tornando-se necessária uma avaliação ampla da informação para possibilitar o uso seguro dos 
medicamentos (CASTRO et al, 1997), além de poderem contribuir na elaboração de boletins dirigidos aos profissionais de saúde e à população em geral.

Este Centro de Informações deveria ser mais amplo para abarcar outros produtos e atender às necessidades da vigilância sanitária.

Este apoio é fundamental para que os órgãos do governo relacionados à vigilância dos produtos para saúde possam tomar a decisão mais acertada. Esta decisão não depende somente do apoio de um centro de informações, mas também da qualidade das notificações como comentado anteriormente.

Para que a agência reguladora de produtos tome a decisão acertada, a partir dos dados de notificação pós-comercialização, a qualidade desta informação deve ser bem acurada e os métodos para avaliar a segurança dos produtos, aperfeiçoados. SHAKIR (2004) acredita que importantes decisões das agências regulatórias são baseadas em informações limitadas e propõe algumas orientações para avaliar a segurança dos produtos.

A freqüente atualização dos dados de segurança das notificações também é colocada por KLEPPER (2004) como importante ferramenta em farmacovigilância, para melhorar inclusive a qualidade das mesmas.

Parece que os hospitais sentinelas sentem mais dificuldades em realizar a notificação em farmacovigilância do que a notificação de queixas técnicas de medicamentos ou de tecnovigilância. Estas últimas em muitos casoss estão relacionadas com a percepção visual (alterações no aspecto, corpo estranho) e, portanto mais simples para preencherem o formulário de notificação.

Já a farmacovigilância é uma atividade que requer mais tempo para realizar a investigação e capacitação técnica, pois envolve vários conhecimentos como, por exemplo, 
de farmacologia e de diagnóstico diferencial sendo imprescindível a participação de um médico.

Diversas ações têm sido implementadas para diminuir a sub-notificação, como o envio aos notificadores de respostas personalizadas descrevendo os resultados da avaliação dos relatos de efeitos adversos por eles enviados ou ainda a validação e acompanhamento conjunto de casos especiais (NUNES, 2000).

A tecnovigilância apesar de ser um campo complexo por envolver diversas tecnologias, as notificações avaliadas neste trabalho, estavam voltadas, principalmente para o problema da qualidade do produto, pois a notificação sobre eventos adversos ou acidentes ainda é incipiente. 


\section{5 - CONCLUSÕES}

As principais conclusões deste trabalho estão descritas a seguir.

Desde a implantação da notificação de eventos adversos a produtos de saúde até o ano de 2004, a ANVISA recebeu 5902 notificações das áreas de farmacovigilância, investigação de queixas técnicas de medicamentos e tecnovigilância.

As notificações da área de tecnovigilância representaram 3 vezes mais o número de notificações da área de farmacovigilância.

Nem todos os Estados da Federação enviaram notificações à ANVISA, por meio dos hospitais sentinelas, no ano de 2004. As áreas de farmacovigilância e de investigação de queixas técnicas de medicamentos receberam notificação de 13 Estados e a área de tecnovigilância de 18 Estados.

Os Estados do Rio Grande do Sul e de São Paulo foram os que mais notificaram, no ano de 2004, para as áreas de farmacovigilância e tecnovigilância. Para a área de queixas técnicas de medicamentos foram os Estados de São Paulo e Rio de Janeiro.

Ocorreram várias oscilações quanto ao número de notificações enviadas à ANVISA durante os meses do ano.

Com relação à amostragem, uma pequena parcela dos hospitais sentinelas notificou à ANVISA, respectivamente quatro hospitais, sete $\mathrm{e}$ oito para as áreas de farmacovigilância, investigação de queixas técnicas de medicamentos e tecnovigilância.

Os profissionais que mais notificaram para as três áreas foram os médicos e os enfermeiros. 
$\mathrm{Na}$ área de farmacovigilância $66,7 \%$ das notificações estavam relacionadas a reações adversas ocorridas no sexo feminino e $57 \%$ estavam na faixa etária compreendida entre 35 e 64 anos. Os grupos farmacológicos envolvidos foram os antineoplásicos e imunomoduladores, os antimicrobianos de uso sistêmico e os agentes do sangue. Com relação à gravidade $20 \%$ foram consideradas graves, $60 \%$ moderadas e $20 \%$ leves. Quanto à causalidade $70 \%$ foram consideradas prováveis e $25 \%$ definidas.

$\mathrm{Na}$ área de investigação de queixas técnicas de medicamentos os grupos farmacológicos envolvidos foram, principalmente, os agentes do sangue, medicamentos que atuam no sistema cardiovascular e no sistema nervoso. Quanto à forma farmacêutica $85,7 \%$ estavam relacionadas a produtos injetáveis. As principais queixas estavam relacionadas à problemas com a rotulagem do produto, presença de corpo estranho, vazamento, ausência de conteúdo e falta de eficácia.

$\mathrm{Na}$ área de tecnovigilância os problemas estavam relacionados, basicamente, com a qualidade dos produtos, sendo que em $89 \%$ dos casos não ocorreu nenhum agravo porque o problema foi detectado antes da utilização do produto. Os principais agravos relatados foram: a contaminação do profissional, do ambiente, perda do medicamento e realização de um mesmo procedimento no paciente mais de uma vez.

Observou-se uma sub-notificação nas três áreas estudadas, especialmente na área de farmacovigilância.

A estratégia de hospitais sentinelas da ANVISA foi muito importante e promoveu um grande impulso para o desenvolvimento da vigilância dos produtos pós comercialização. 
A qualidade dos produtos, no Brasil, ainda é um problema, não só para medicamentos onde já existem, tradicionalmente, programas de inspeção na indústria farmacêutica como, também, para a área de produtos médicos que iniciou, mais recentemente, seu programa de inspeção em indústrias que produzem produtos de alto risco, como por exemplo, os implantes.

Para que os eventos adversos possam subsidiar as ações de vigilância em saúde, deve-se trabalhar com um conceito amplo, onde se englobe qualquer problema relacionado a produtos, seja relacionada à qualidade, intoxicação (no caso de medicamentos), utilização incorreta, erros ou reações adversa oriundas da interação produto-indivíduo. A estratégia de gerência de risco adotada nos hospitais sentinelas tem todas as condições para trabalhar desta forma.

A estrutura de Gerente de risco poderia se reproduzir nos âmbitos dos Governos Federal, Estadual e Municipal, a fim de que esta gerência possa coordenar as diversas áreas que recebem as notificações de produtos, bem como integrar as iniciativas de coleta, análise e sistematização de eventos adversos de outras instituições, externas à área regulatória, normatizar procedimentos para avaliação do risco, estabelecer fluxos, divulgar informações sobre a segurança dos produtos dentre outras. 


\section{6 - CONSIDERAÇÕES FINAIS}

A informação gerada das notificações de produtos de saúde deve ser utilizada para educação continuada dos profissionais de saúde e também deve-se gerar informação dirigida à população em geral.

É preciso continuar investindo como vem fazendo a ANVISA em capacitação para não só incluir mais hospitais sentinelas, como também para melhorar a qualidade das notificações existentes e estimular que os profissionais notifiquem. Ressalta-se a importância da vigilância ter o suporte de um Centro de Informações não somente para medicamentos como, também, para produtos de saúde para contribuir nas decisões que devam ser tomadas.

É necessário disponibilizar essas informações para os Estados e municípios, para que estes executem as ações de vigilância e possam utiliza-las como ferramentas importantes, principalmente para a avaliação da qualidade dos produtos planejando melhor suas acões. 


\section{7 - REFERÊNCIAS}

1. Abajo FJ. El medicamento como solución y como problema para la salud pública. Una breve incursión a los objetivos de la farmacoepidemiología. Rev Esp Salud Publica Ago 2001; 75 (4): 281-84.

2. Adati MC, Brito EB, Vigo DC, Ribeiro AS, Mendonça VF, Souza VS et al. Monitoramento da qualidade de hemoderivados importados e nacionais utilizados no país [resumo]. Rev.bras. epidemiol 2002 a; 5 (Supl. Esp.): 60. [Apresentado no Simpósio Brasileiro de Vigilância Sanitária; 2002 dez 2-4; São Paulo].

3. Adati MC, Borges HCBG, Ribeiro AS, Mendonça VS, Souza VS, Brito EB. Análise de produtos de interesse em serviços de hemoterapia (1998 a 2002). [resumo]. Rev.bras. epidemiol 2002 b; 5 (Supl. Esp.): 48. [Apresentado no Simpósio Brasileiro de Vigilância Sanitária; 2002 dez 2-4; São Paulo].

4. Agência Nacional de Vigilância Sanitária (ANVISA). Resolução n. 1 de 26 de abril de 1999. Aprova o Regimento e Quadro de Distribuição de Cargos em Comissão e Funções Comissionadas de Vigilância Sanitária da Agência de Vigilância Sanitária. Diário Oficial da República Federativa do Brasil, Brasília, 27 abr 1999.

5. Agência Nacional de Vigilância Sanitária (ANVISA). Portaria 593 de 25 de agosto de 2000. Aprova o Regimento Interno e o Quadro Demonstrativo de Cargos em Comissão da Agência Nacional de Vigilância Sanitária. Diário Oficial da República Federativa do Brasil, Brasília, 28 agosto 2000.

6. Agência Nacional de Vigilância Sanitária (ANVISA). Portaria n. 239 de 17 de maio de 2001. Altera o Anexo III da Portaria $\mathrm{n}^{\circ}$ 593, de 25 de agosto de 2000; altera os artigos $4^{\circ}, 30,31,32$ e 90 do Anexo II da Portaria n ${ }^{\circ} 593$, de 25 de agosto de 2000; revoga os artigos 45 e 52 do Anexo II da Portaria $n^{\circ}$ 593, de 25 de agosto de 2000; insere os artigos 58-A, 92-A e 92-B no Anexo II da Portaria n ${ }^{\circ} 593$, de 25 de agosto de 2000; altera o Anexo I da Portaria ${ }^{\circ} 228$, de 04 de maio de 2001. Diário Oficial da República Federativa do Brasil, Brasília, 21 maio 2001a.

7. Agência Nacional de Vigilância Sanitária (ANVISA). Resolução de diretoria colegiada. RDC n. 185 de 22 de outubro de 2001. Aprova o Regulamento Técnico que consta no anexo desta Resolução, que trata do registro, alteração, revalidação e cancelamento do registro de produtos médicos na Agência Nacional de Vigilância Sanitária. Diário Oficial da República Federativa do Brasil, Brasília, 24 outubro $2001 b$.

8. Agência Nacional de Vigilância Sanitária (ANVISA). Portaria 385 de 04 de junho de 2003. Altera Anexo I da Portaria $n^{\circ} 326$, de 16 de maio de 2003, que passa a vigorar com a redação do Anexo I desta Portaria. Diário Oficial da República Federativa do Brasil, Brasília, 17 junho 2003. 
9. Agência Nacional de Vigilância Sanitária (ANVISA). Portaria n. 123 de 09 de fevereiro de 2004. Atualiza o regimento interno da ANVISA. Diário Oficial da República Federativa do Brasil, Brasília, 10 fevereiro 2004a.

10. Agência Nacional de Vigilância Sanitária (ANVISA). Política vigente para a regulamentação de medicamentos no Brasil, Brasília, 2004b.

11. Agência Nacional de Vigilância Sanitária (ANVISA). Gerência Geral de Segurança Sanitária de Produtos de Saúde Pós Comercialização. Unidade de Tecnovigilância. Consulta sobre alertas de tecnovigilância; 2005a. Disponível em: http://www.anvisa.gov.br/sistec/alerta/consultaralerta.asp [09/05/2005].

12. Agência Nacional de Vigilância Sanitária (ANVISA). Gerência Geral de Segurança Sanitária de Produtos de Saúde Pós Comercialização. Unidade de Tecnovigilância. Consulta sobre alertas de tecnovigilância; 2005b. Disponível em: http://www.anvisa.gov.br/sistec/alerta/RelatorioAlerta.asp?NomeColuna=CO_SEQ ALERTA\&Parametro $=768$ [09/05/2005].

13. Agência Nacional de Vigilância Sanitária (ANVISA). Serviços de saúde. Hospitais Sentinelas. Gerentes de Risco Sanitário Hospitalar; 2005c. Disponível em: http://www.anvisa.gov.br/servicosaude/hsentinela/gerente risco.htm [09/05/2005].

14. Agência Nacional de Vigilância Sanitária (ANVISA). Serviços de saúde. Hospitais Sentinelas. Situação da rede dos Hospitais Sentinelas; 2005d. Disponível em: http://www.anvisa.gov.br/servicosaude/hsentinela/ppt/apresenta_GR_v2230903.ppt [09/05/2005].

15. Antunes E, Vale M, Mordelet $\mathrm{P}$, Grabois V. Gestão da tecnologia biomédica: tecnovigilância e engenharia clínica. Paris: Acodess; 2002.

16. Araújo MC. Certificação de equipamentos eletromédicos no Brasil [resumo]. Rev.bras. epidemiol 2002; 5 (Supl. Esp.): 95. [Apresentado no Simpósio Brasileiro de Vigilância Sanitária; 2002 dez 2-4; São Paulo].

17. Backstrom M, Mjorndal $T$, Dahlqvist $R$. Under reporting of serious adverse reactions in Sweden. Pharmacoepidemiology and drug safety 2004; 13: 483-87.

18. Barros JAC. Políticas famacêuticas: a serviço dos interesses da saúde?. Brasília: UNESCO; 2004.

19. Basile AC, Zanini AC. Dicionário de medicamentos genéricos. São Roque: Ipex Editora, 1999. 
20. Bérard A, Malouin A, Oraichi D, Gauthier L, Pellerin A, Martin B et al. Medication use during the first trimester of pregnancy [abstract]. Pharmacoepidemiology and drug safety july 2004; 13 (1 Suppl): 221. [Presented at $20^{\text {th }}$ International Conference on Pharmacoepidemiology \& Therapeutic Risk Management; 2004 Aug 22-25; Bordeaux].

21. Bertulyte I, Gulbinovic J. Adverse drug reactions and other drug related problems as a cause of hospital admission: a retrospective study [abstract]. Pharmacoepidemiology and drug safety july 2004; 13 (1 Suppl): 111. [Presented at $20^{\text {th }}$ International Conference on Pharmacoepidemiology \& Therapeutic Risk Management; 2004 Aug 22-25; Bordeaux].

22. Bispo MRO, de Paula NC, Neiva IAS, Pfrimer P, Filho EAF. Avaliação da qualidade microbiológica $\mathrm{e}$ da rotulagem dos medicamentos fitoterápicos comercializados no Estado de Goiás [resumo]. Rev.bras. epidemiol 2002; 5 (Supl. Esp.): 93. [Apresentado no Simpósio Brasileiro de Vigilância Sanitária; 2002 dez 24; São Paulo].

23. Brasil. Lei n. 6360 de 23 de setembro de 1976. Dispõe sobre a vigilância sanitária a que ficam sujeitos os medicamentos, as drogas, os insumos farmacêuticos e correlatos, cosméticos, saneantes e outros produtos e dá outras providências. Diário Oficial da República Federativa do Brasil, Brasília, 24 set 1976.

24. Brasil. Lei n. 9782 de 26 de janeiro de 1999. Define o Sistema Nacional de Vigilância Sanitária, cria a Agência Nacional de Vigilância Sanitária e dá outras providências. Diário Oficial da República Federativa do Brasil, Brasília, 27 jan 1999.

25. Brasil. Decreto n. 3029 de 16 de abril de 1999. Aprova o regulamento da Agência Nacional de Vigilância Sanitária e dá outras providências. Diário Oficial da República Federativa do Brasil, Brasília, 19 abr 1999.

26. Brasil. Constituição da República Federativa do Brasil. $27^{\mathrm{a}}$ ed. São Paulo: Saraiva; 2001.

27. Brown SL, Woo EK. Surgical stapler-associated fatalities and adverse events reported to the Food and Drug Administration. J Am Coll Surg 2004; 199 (3): 37481.

28. Carlini ELA, Nappo AS . The pharmacovigilance of psychooactive medications in Brazil. Rev Bras Psiquiatr 2003; 25 (4): 200-05.

29. Carvalho PR, Carvalho CG, Alievi PT, Martinbiancho J, Trotta EA. Identificação de medicamentos não apropriados para crianças em prescrições de unidade de tratamento intensivo pediátrica. J Pediatr (Rio de Janeiro) 2003; 79: 397-402. 
30. Cassiani SHDEB, Ueta J, organizadoras. A segurança de pacientes na utilização da medicação. São Paulo: Artes Médicas; 2004.

31. Castel MJ, Figueras A, Pedrós C, Laporte JR, Capellà D. Stimulating adverse drug reaction reporting. Drug Safety 2003; 26 (14): 1049-55.

32. Castro LLC. Farmacoepidemiologia uma nova disciplina. Divulg. Saúde Debate 1997; 18: 87-92.

33. Castro LLC, Baraza AMC, Monreal MT, Toledo MI. Serviço de informação de medicamentos: estratégias para o desenvolvimento da farmacoepidemiologia no país. In: Bonfim JRA, Mercucci VL, organizadores. A construção da política de medicamentos. São Paulo: Hucitec-Sobravime; 1997. p.178-80.

34. Castro LLC. Farmacoepidemiologia: uma nova disciplina. In: Castro LLC organizadora. Fundamentos de farmacoepidemiologia. Grupo de pesquisa em uso racional de medicamentos (GRUPURAM); 2000. p. 6-18.

35. Castro LLC, Oshiro ML, Vicente MG, Cymrot R. Revisão retrospectiva de prontuários como estratégia de farmacovigilância. Saúde Rev (Piracicaba) Jan/Abr 2004; 6 (12): 1-75.

36. Centers for Disease Control and Prevention (CDC). Division of Public Health Surveillance and Informatics. Epidemiology Program Office; 2005. Disponível em: http://www.cdc.gov/epiinfo/Epi6/ei6.htm [07/01/2005].

37. CERTs - the centers for education and research on therapeutics risk assessment workshop participants. Pharmacoepidemiology and drug safety 2003; 12: 653-62.

38. Chambers CD, Johnson DL, Macaraeg GR, Jones KL. Pregnancy outcome following early gestational exposure to leflunomide: the otis rheumatoid arthritis in pregnancy study [abstract]. Pharmacoepidemiology and drug safety july 2004; 13 (1 Suppl): 126. [Presented at $20^{\text {th }}$ International Conference on Pharmacoepidemiology \& Therapeutic Risk Management; 2004 Aug 22-25; Bordeaux].

39. Chan D, Bishoff JT, Ratner L. Endovascular gastrointestinal stapler device malfunction during laparoscopic nephrectomy: early recognition and management. J Urol 2000; 164: 319-21.

40. Coêlho HL. Farmacovigilância: um instrumento necessário. Cad Saúde Pública 1998; 14 (4): 871-75. 
41. Cooper WO, Hernandez- Dias S, Ray WA. Positive predictive value of computerized data bases for birth defects in a medicaid population [abstract]. Pharmacoepidemiology and drug safety july 2004; 13 (1 Suppl): 127. [Presented at $20^{\text {th }}$ International Conference on Pharmacoepidemiology \& Therapeutic Risk Management; 2004 Aug 22-25; Bordeaux].

42. Costa EA. Vigilância sanitária: proteção e defesa da saúde. $2^{\mathrm{a}}$ ed. São Paulo: Sociedade Brasileira de Vigilância de Medicamentos; 2004.

43. Cunnington MC, Weil JG, Cragan J. A 2004 review of pregnancy outcome datasources [abstract]. Pharmacoepidemiology and drug safety july 2004; 13 (1 Suppl): 222. [Presented at $20^{\text {th }}$ International Conference on Pharmacoepidemiology \& Therapeutic Risk Management; 2004 Aug 22-25; Bordeaux].

44. Devi DP, Sushma M, Guido S. Drug-induced upper gastrointestinal disorders requiring hospitalization: a five-year study in a South Indian hospital. Pharmacoepidemiol Drug Saf 2004; 13 (12):859-62.

45. Dias DD. Intoxicações por medicamentos em crianças de 0 a 12 anos notificados no CIT/GO de 1998 a 2000 [resumo]. Rev.bras. epidemiol 2002; 5 (Supl. Esp.): 138. [Apresentado no Simpósio Brasileiro de Vigilância Sanitária; 2002 dez 2-4; São Paulo].

46. Dias MF, Tolentino M, Figueiredo PM de, Vila-Inda CJ da, Lacerda E, Leite FQ et al. Notificações de suspeitas de reação adversa a medicamento para a Unidade de Farmacovigilância - ANVISA no primeiro semestre de 2002. [resumo]. Rev.bras. epidemiol 2002; 5 (Supl. Esp.): 140. [Apresentado no Simpósio Brasileiro de Vigilância Sanitária; 2002 dez 2-4; São Paulo].

47. Dias MF. A Agência Nacional de Vigilância Sanitária e o Sistema Nacional de Farmacovigilância. Boletim Epidemiológico Paulista (BEPA). São Paulo: Coordenadoria de Controle de Doenças da Secretaria de Estado da Saúde de São Paulo; 2005. (Informe mensal sobre agravos à saúde pública, Ano 2, nº 16).

48. Domínguez LES, Beguiristaín HJD, Cruz JRP, Mayo JD. Adverse drug reaction in a intensive care unit [abstract]. Pharmacoepidemiology and drug safety july 2004; 13 (1 Suppl): 120. [Presented at $20^{\text {th }}$ International Conference on Pharmacoepidemiology \& Therapeutic Risk Management; 2004 Aug 22-25; Bordeaux].

49. Donoso AF, Fuentes IR. Eventos adversos en UCI. Rev chil. Pediatr Mayo 2004; 75 (3): 233-39.

50. Dormann H, Criegee-Rieck M, Neubert A, Egger T, Geise A, Krebs S et al. Lack of awareness of community-acquired adverse drug reactions upon hospital admission. Drug Safety 2003; 26 (5): 353-62. 
51. Eduardo MBP. O poder da ação da vigilância sanitária e os resultados em benefício da saúde. In: Vigilância Sanitária. v 8. São Paulo: FSP/USP; 1998. p 247-51 (coleção saúde e cidadania).

52. Edwards R, Aronson JK. Adverse drug reactions: definitions, diagnosis, and management. Lancet 2000; 356: 1255-59.

53. Gherardini G, Zaccheddu R, Basoccu G. Trilucent breast implants: voluntary removal following the medical device agency recommendation. Report on 115 consecutive patients. Plast Reconstr Surg 2004; 113 (3): 1024-27.

54. Giachetto G, Banchero P, Telechea H, Speranza N, Wolaj M, Toledo M et al. Uso racional de medicamentos: qué conocen los médicos residentes sobre los fármacos de uso corriente? Rev Med Uruguay 2003; 19: 231-36.

55. Gomes SMT, Nogueira V, Fontes RS, Araújo JF, Hofmeister MGS, Bezerra ACC. Vigilância da qualidade de medicamentos: comunicação de suspeita de irregularidade [resumo]. Rev.bras. epidemiol 2002; 5 (Supl. Esp.): 107. [Apresentado no Simpósio Brasileiro de Vigilância Sanitária; 2002 dez 2-4; São Paulo].

56. Gomes SMT, Lima KD, Doi AS, Nunes AA, Hofmeister MGS, Bezerra ACC. Ineficácia terapêutica: falha no processo produtivo ou assistência farmacêutica inadequada? [resumo]. Rev.bras. epidemiol 2002a; 5 (Supl. Esp.): 25. [Apresentado no Simpósio Brasileiro de Vigilância Sanitária; 2002 dez 2-4; São Paulo].

57. Gouveia R. Saúde Pública, suprema lei: a nova legislação para a conquista da saúde. São Paulo: Mandacaru; 2000.

58. Greenfield LJ. Medical device adverse event reports and the food and drug administration [Editorial]. J Vasc Surg 2004; 40 (2): 395-6.

59. Grohmann R; Hippius H; Helmchen H; Rüther E; Schmidt LG. The AMUP study for drug surveillance in psychiatry - a summary of inpatient data Pharmacopsychiatry 2004; 37 Suppl 1:S16-26.

60. Guerra Jr AA, Silva SS, Castro UR, Silver LD. Falsificação de medicamentos estudo sobre a crise brasileira de 1998 [resumo]. Rev.bras. epidemiol 2002; 5 (Supl. Esp.): 110. [Apresentado no Simpósio Brasileiro de Vigilância Sanitária; 2002 dez 2-4; São Paulo]. 
61. Hardy JR, Leaderer BP, Holford TR, Hall GC, Bracken MB. Medications prescribed before and during early pregnancy in a cohort of 81975 mother-baby pairs: a population based study using the automated date of the general practice research database [abstract]. Pharmacoepidemiology and drug safety july 2004; 138 (1 Suppl): 31. [Presented at $20^{\text {th }}$ International Conference on Pharmacoepidemiology \& Therapeutic Risk Management; 2004 Aug 22-25; Bordeaux].

62. Headley JE. Medication use during pregnancy: data from the avon longitudinal study of parents and children [abstract]. Pharmacoepidemiology and drug safety july 2004; 241 (1 Suppl): 31. [Presented at $20^{\text {th }}$ International Conference on Pharmacoepidemiology \& Therapeutic Risk Management; 2004 Aug 22-25; Bordeaux].

63. Holsbach LR, Guimarães LBM, Cardoso PFG. Metodologia de investigação de acidentes com equipamentos médicos em ambiente cirúrgico [resumo]. Rev.bras. epidemiol 2002; 5 (Supl. Esp.): 71. [Apresentado no Simpósio Brasileiro de Vigilância Sanitária; 2002 dez 2-4; São Paulo].

64. Karande S, Gogtay NJ, Kshirsagar NA. Improving Drug Safety Monitoring. Indian Pediatrics 2003; 40:1167-1175.

65. Kauchal R, Bates DW, Landrigan C, McKenna KJ, Clapp MD, Federico F et al. Medications errors and adverse drug events in pediatric inpatients. JAMA 2001; 285: 2114-20.

66. Klepper MJ. The periodic safety update report as pharmacovigilance tool. Drug Safety 2004; 27 (8):569-78.

67. Koo LC, Clark JÁ, Higenbottam T, Nyberg F, Wolf MK, Steinberg MH. National differences in reporting "pneumonia" and pneumonia interstitial": an analysis of the WHO adverse events database on 15 drugs in 9 countries for 7 pulmonary conditions [abstract]. Pharmacoepidemiology and drug safety july 2004; 13 (1 Suppl): 31 . [Presented at $20^{\text {th }}$ International Conference on Pharmacoepidemiology \& Therapeutic Risk Management; 2004 Aug 22-25; Bordeaux].

68. Lacerda E, Rumel D, Dias MF, Souza NR, Figueiredo PM, Dourado LG et al. Avaliação das notificações de queixas técnicas de medicamentos da unidade de farmacovigilância - Anvisa no período de janeiro a setembro de 2002 [resumo]. Rev.bras. epidemiol 2002; 5 (Supl. Esp.): 135. [Apresentado no Simpósio Brasileiro de Vigilância Sanitária; 2002 dez 2-4; São Paulo]. 
69. Lacroix I, Cabou C, Montastruc JL, Damase-Michel C. Adverse drug reactions in pregnant women [abstract]. Pharmacoepidemiology and drug safety july 2004; 13 (1 Suppl): 221. [Presented at $20^{\text {th }}$ International Conference on Pharmacoepidemiology \& Therapeutic Risk Management; 2004 Aug 22-25; Bordeaux].

70. Laporte JR, Tognoni G. Principios de epidemiología del medicamento. $2^{\circ}$ ed. Barcelona: Masson -Salvat Medicina; 1993.

71. Laurence DR, Carpenter JR. A dictionary of pharmacology and clinical drug evaluation. London: UCL Press, 1994. p 6.

72. Levesque L, Hemmelgarn B, Suissa S. Anti diabetic drug use and the risk of motor vehicle crash in the elderly [abstract]. Pharmacoepidemiology and drug safety july 2004; 13 (1 Suppl): 130 . [Presented at $20^{\text {th }}$ International Conference on Pharmacoepidemiology \& Therapeutic Risk Management; 2004 Aug 22-25; Bordeaux].

73. Liu BA; Knowles SR; Mittmann N; Einarson T; Shear NH. Reporting of fatal adverse drug reactions. Can J Clin Pharmacol 2001; 8 (2):84-8.

74. Livry C, Disson-Dautriche A, Jolimoy G, Tabutiaux A, Sgro C. Identification du mésusage des medicaments. Press Med 2003; 32:1552-56.

75. López MJO. Errores de medicación y gestión de riesgos. Rev Esp Salud Publica Oct 2003; 77 (5): 527-40.

76. Louik C, Honein MA, Werler MM, Mitchell AA . Use of herbal products during pregnancy [abstract]. Pharmacoepidemiology and drug safety july 2004; 13 (1 Suppl): 157. [Presented at $20^{\text {th }}$ International Conference on Pharmacoepidemiology \& Therapeutic Risk Management; 2004 Aug 22-25; Bordeaux].

77. Louro E. Eventos adversos a antibióticos em pacientes internados no setor de clínica médica do Hospital Universitário Regional de Maringá-PR. São Paulo; 2004. [ Dissertação de mestrado apresentada à Faculdade de Saúde Pública da USP].

78. Luna JB, Silva LFF, Rodrigues MAS. Perfil da qualidade dos medicamentos na forma farmacêutica de soluções e suspensões orais, analisados na Dimed do LacenPE [resumo]. Rev.bras. epidemiol 2002; 5 (Supl. Esp.): 105. [Apresentado no Simpósio Brasileiro de Vigilância Sanitária; 2002 dez 2-4; São Paulo]. 
79. MacKay I, Garrah J, Tabah B, Freeman L, Maher M, Macdonald L. Adverse drug reactions associated with the use of ribavirin in the treatment of severe acute respiratory syndrome (SARS) [abstract]. Pharmacoepidemiology and drug safety july 2004; 13 (1 Suppl): 31 . [Presented at $20^{\text {th }}$ International Conference on Pharmacoepidemiology \& Therapeutic Risk Management; 2004 Aug 22-25; Bordeaux].

80. Maisel WH. Medical device regulation: an introduction for the practicing physician. Ann Intern Med 2004; 140 (4): 296-302.

81. Mastroianni PC, Galduróz JCF, Carlini EA. Influence of the legislation on the advertisement of psychoactive medications in Brazil. Rev. Bras. Psiquiatr. Sept 2003; 25 (3): 146-55.

82. McEwen J. Risk management from an Ásia/ Pacific rim regulatory perspective. Drug Safety 2004; 27 (8): 491-97.

83. Mejía R, Avalos A . Material informativo entregado por los agentes de propaganda medica. Medicina (B. Aires) 2001; 61 (3): 315-18.

84. Menniti-Ippolito F, Traversa G, Da Cas R, Vetrano F, Saggiomo G, Menna F et al. Gastroduodenal adverse reactions to drug in children in Italy [abstract]. Pharmacoepidemiology and drug safety july 2004; 141 (1 Suppl): 31 . [Presented at $20^{\text {th }}$ International Conference on Pharmacoepidemiology \& Therapeutic Risk Management; 2004 Aug 22-25; Bordeaux].

85. Ministério da Saúde. Portaria n 2043 de 12 de dezembro de 1994 Institui o Sistema de Garantia da Qualidade de produtos correlatos submetidos ao regime da Lei $\mathrm{n}^{\circ}$ 6.360, de 27 de setembro de 1976 e o Decreto $n^{\circ} 79.094$, de 05 de janeiro de 1977 . Diário Oficial da República Federativa do Brasil, Brasília, 13 dez 1994

86. Ministério da Saúde. Portaria n. 2661 de 20 de dezembro de 1995. Altera o item 4 da Portaria $\mathrm{n}^{\circ} 2.043$, de 12 de dezembro de 1994, o qual passa a vigorar com a redação disposta nesta Portaria. Diário Oficial da República Federativa do Brasil, Brasília, 22 dez 1995.

87. Miranda MCC \& Rozenfeld S. Reações adversas não alérgicas da suspensão injetável da benzilpenicilina benzatina : uma revisão sistemática [resumo]. Rev.bras. epidemiol 2002; 5 (Supl. Esp.): 106. [Apresentado no Simpósio Brasileiro de Vigilância Sanitária; 2002 dez 2-4; São Paulo].

88. Mittmann N, Knowles SR, Gómez M, Fish JS, Cartotto R, Shear NH. Evaluation of the extent of under reporting of serious adverse drug reactions. Drug Safety 2004; 27 (7): 477-87. 
89. Moralesd M, Ruiza I, Morgadoc C, González X. Farmacovigilancia en Chile y el mundo. Rev chil infectol 2002; 19 (suppl 1): S42-45.

90. Moseley JNS. Risk management. Drug Safety 2004; 27 (8): 499-508.

91. Nascimento MC. Medicamentos: ameaça ou apoio à saúde?: vantagens e perigos do uso de produtos da indústria farmacêutica mais consumidos no Brasil: vitaminas, analgésicos, antibióticos e psicotrópicos. Rio de Janeiro: Vieira \& Lent; 2003.

92. Navarro FA. Dicionário critico de dudas inglês-español de medicina. $4^{\circ} \mathrm{ed}$. Madrid: Mc Graw Hill- Interamericana; 2002. p 171 e 464.

93. Nunes AMC. Conceitos básicos de farmacovigilância. In: Castro LLC organizadora. Fundamentos de farmacoepidemiologia. Grupo de pesquisa em uso racional de medicamentos (GRUPURAM); 2000. p. 107-126.

94. Oraichi D, Bérard A . Development of a surveillance and signal detection system to monitor medication exposure during pregnancy and lactation [abstract]. Pharmacoepidemiology and drug safety july 2004; 13 (1 Suppl): 127. [Presented at $20^{\text {th }}$ International Conference on Pharmacoepidemiology \& Therapeutic Risk Management; 2004 Aug 22-25; Bordeaux].

95. Organización Mundial de la Salud. Promoción del uso racional de medicamentos: componentes centrales. Perspectivas politicas sobre medicamentos de la OMS; 2002. http://www.who.int/medicines/library/edm-general/6 pagers/ppm05sp.pdf. [14/07/2004]

96. Pfaffenbach G., Carvalho OM, Bergsten-Mendes G. Reações adversas a medicamentos como determinantes da admissão hospitalar. Rev. Assoc. Méd. Bras. Set 2002; 48 (3): 237-41.

97. Ponciano AM de S, Carvalho DM de, Santos EP dos. Avaliação do nível de informação do estudo das reações adversa a medicamentos em um hospital universitário. Cad. Saúde Colet. 1998; 6 (1): 5-23.

98. PR Vademecum. $7^{\circ}$ ed. São Paulo: Soriak; 2001/2002.

99. Puijenbroek Epvan, Grootheest Kvan, Diemont WL, Leufkens HGM, Egberts ACG. Determinants of signal selection in a spontaneous reporting system for adverse drug reactions. Br J Clin Pharmacol 2001; 52: 579-86.

100. Ranganathan SS, Houghton JE, Davies DP, Routledge PA. The involvement of nurses in reporting suspected adverse drug reactions: experience with the meningococcal vaccination scheme. Br J Clin Pharmacol 2003; 56: 658-63. 
101. Rawlins MD. Educación y formación para el uso racional de los medicamentos por el personal de salud y por la población. In: Organización Mundial de la Salud. Uso racional de los medicamentos. Ginebra, 1986. p 276-84 (Informe de la conferencia de expertos - Nairobi, 1985).

102. Rozenfeld S. Reações Adversas aos Medicamentos em Mulheres da Terceira Idade as Quedas como Iatrogenia Farmacoterapêutica. Rio de Janeiro; 1997 [Tese de Doutorado,: Instituto de Medicina Social, Universidade Estadual do Rio de Janeiro].

103. Rozenfeld S. Farmacovigilância: elementos para a discussão e perspectivas. Cad Saúde Pública (Rio de Janeiro) 1998; 14 (2): 237- 63.

104. Rozenfeld $\mathrm{S}$ organizadora. Fundamentos da vigilância sanitária. Rio de Janeiro: Fiocruz; 2000.

105. Ruiz-Jarabo, Instituto para el uso seguro de los medicamentos, Sociedad Española de Farmacia Hospitalaria. Terminología 2000. Disponível em: http://www3.usal.es/ ismp/terminologia.pdf [20 Janeiro 2005].

106. Samore MH, Evans RS, Lassen A . Surveillance of medical device-related hazards and adverse events in hospitalized patients. JAMA 2004; 291 (3): 325-34.

107. Santell JP, Hicks RW, McMeekin J, Cousins DD. Medications errors: experience of the United States Pharmacopeia (USP) Medmarx reporting system. J Clin Pharmacol 2003; 43: 760-67.

108. Santi V. Medicamentos: verso e reverso da propaganda. Ponta Grossa: UEPG; 1999.

109. Santos AE. Eventos adversos com medicações em serviços de emergências: condutas profissionais e sentimentos vivenciados por enfermeiros. São Paulo; 2002. [Dissertação apresentada à Escola de Enfermagem da Universidade de São Paulo].

110. Schack BK. Quality management in pharmacovigilance: effects on quality of reports [abstract]. Pharmacoepidemiology and drug safety july 2004; 13 (1 Suppl): 115 . [Presented at $20^{\text {th }}$ International Conference on Pharmacoepidemiology \& Therapeutic Risk Management; 2004 Aug 22-25; Bordeaux].

111. Schmickler MR. Adverse event report in paediatrics [abstract]. Pharmacoepidemiology and drug safety july 2004; 13 (1 Suppl): 114. [Presented at $20^{\text {th }}$ International Conference on Pharmacoepidemiology \& Therapeutic Risk Management; 2004 Aug 22-25; Bordeaux]. 
112. Segura O, Maldonado CE. Las reacciones adversas a medicamentos: uma aproximación desde el punto de vista económico. Biomedica 2003; 23: 401-7.

113. Serreau R, Boissinot C, Sibony O, Gilbert A, Jacqz-Aigrain E. Drugs and breastfeeding: a french collaboration in a pharmacoepidemiology study [abstract]. Pharmacoepidemiology and drug safety july 2004; 13 (1 Suppl): 222. [Presented at $20^{\text {th }}$ International Conference on Pharmacoepidemiology \& Therapeutic Risk Management; 2004 Aug 22-25; Bordeaux].

114. Sevalho G. Debate sobre o artigo de Suely Rozenfeld. In: Rozenfeld S. Farmacovigilância: elementos para a discussão e perspectivas. Cad Saúde Pública (Rio de Janeiro) 1998; 14 (2): 255-57.

115. Shakir SAW, Smith L, Clarke A . Decision-making and evidence based pharmacovigilance [abstract]. Pharmacoepidemiology and drug safety july 2004; 13 (1 Suppl): 128. [Presented at $20^{\text {th }}$ International Conference on Pharmacoepidemiology \& Therapeutic Risk Management; 2004 Aug 22-25; Bordeaux].

116. Silva MM, Menezes RF. O Centro de Vigilância Sanitária do Estado de São Paulo e o Sistema Estadual de Farmacovigilância. Boletim Epidemiológico Paulista (BEPA). São Paulo: Coordenadoria de Controle de Doenças da Secretaria de Estado da Saúde de São Paulo; 2005. (Informe mensal sobre agravos à saúde pública, Ano 2, $\mathrm{n}^{\circ} 16$ ).

117. Silva TM. Implantes ortopédicos: uma política de vigilância sanitária [resumo]. Rev.bras. epidemiol 2002; 5 (Supl. Esp.): 72. [Apresentado no Simpósio Brasileiro de Vigilância Sanitária; 2002 dez 2-4; São Paulo].

118. Small SD. Medical device-associated safety and risk: surveillance and stratagems. JAMA 2004; 291 (3): 367-70.

119. Souto AC. Saúde e política: A vigilância sanitária no Brasil:1976-1994. São Paulo: Sociedade Brasileira de Vigilância de Medicamentos; 2004.

120. Stephens PRS, Neto ER, Costa JAC, Costa CI, Werneck LMC, Leal EC. O papel do Instituto Nacional de Controle de Qualidade em Saúde INCQS/FIOCRUZ na avaliação laboratorial de vacinas e soros utilizados no programa nacional de imunizações [resumo]. Rev.bras. epidemiol 2002; 5 (Supl. Esp.): 102. [Apresentado no Simpósio Brasileiro de Vigilância Sanitária; 2002 dez 2-4; São Paulo].

121. Strom BL. What is Pharmacoepidemiology? In: Strom BL, editor. Pharmacoepidemiology. 3nd ed. Chichester: John Wiley \& Sons; 2000. p.3, 5. 
122. Taraska I. Validação de técnica de reprocessamento de artigo de uso único em uma clínica de hemodiálise em Curitiba - Paraná [resumo]. Rev.bras. epidemiol 2002; 5 (Supl. Esp.): 25. [Apresentado no Simpósio Brasileiro de Vigilância Sanitária; 2002 dez 2-4; São Paulo].

123. Temple ME; Robinson RF; Miller JC; Hayes JR; Nahata MC. Frequency and preventability of adverse drug reactions in paediatric patients. Drug Saf 2004; 27 (11):819-29.

124. Tisonová J, Szalayová A, Kriska M, Gibala P, Foltán V. Factors influencing the spontaneous reporting of adverse drug reactions - the experience of the Slovak Republic. Pharmacoepidemiology and drug safety 2004; 13 (5): 333-37.

125. Tsintis $\mathrm{P}$, Mache E. CIOMS and ICH initiatives in pharmacovigilance and risk management. Drug Safety 2004; 27 (8): 509-17.

126. Uppsala Monitoring Centre. WHO Collaborating Centre for International Drug Monitoring. Definitions: Causality assessment of suspected adverse reactions; 2005. Disponível em: http://www.who-umc.org/index2.html [09/05/2005].

127. Valente LAM, Silva TM, Shuqair N. A situação dos produtos para saúde (correlatos) no Brasil: reclamação, denúncia e a situação das empresas no país [resumo]. Rev.bras. epidemiol 2002; 5 (Supl. Esp.): 47. [Apresentado no Simpósio Brasileiro de Vigilância Sanitária; 2002 dez 2-4; São Paulo].

128. Vidotti CCF. Centro Brasileiro de Informações sobre medicamentos (Cebrim). In: Bonfim JRA, Mercucci VL, organizadores. A construção da política de medicamentos. São Paulo: Hucitec-Sobravime; 1997. p.158- 63.

129. Weingart SN, Wilson RMcL, Gibberd RW, Harrison B. Epidemiology of medical error. BMJ 2000; 320: 774-77.

130. Wiholm BE, Martinez C, Mitchel A, Chambers C. European vs American approach to assessing human teratogens- is one better than the other [abstract]. Pharmacoepidemiology and drug safety july 2004; 13 (1 Suppl): 148. [Presented at $20^{\text {th }}$ International Conference on Pharmacoepidemiology \& Therapeutic Risk Management; 2004 Aug 22-25; Bordeaux].

131. WHOa :. WHO Collaborating Centre for International Drug Monitoring. The importance of pharmacovigilance: safety monitoring of medicinal products. Geneva: WHO; 2002.

132. WHOb. Safety of medicines: a guide to detecting and reporting adverse drug reactions. Geneva: WHO; 2002. 
133. WHOc Collaborating Centre for Drug Statistics Methodology. Norwegian Institute of Public Health. Oslo; 2005. Disponível em: http://www.whocc.no. [10/01/2005].

134. WHOd. Essential drugs and medicines policy: good manufacturing practice (GMP) in pharmaceutical production; 2005. Disponível em: http://www.who.int/medicines/organization/qsm/activities/qualityassurance/gmp/or ggmp.shtme. [12/05/2005].

135. Wolfe SM, Sasich LD, Hope RE. Worst pills, best pills: a consumer's guide to avoiding drug-induced death or illness. New York: Pocket Books; 1999.

136. Zubioli A . Ética farmacêutica. São Paulo: Sociedade Brasileira de Vigilância de Medicamentos; 2004. 


\section{ANEXOS}


ANEXO 1 - RELAÇÃO DE HOSPITAIS SENTINELAS (ANVISA, 2005d)

RORAIMA

Boa Vista

Hospital Rubens de Souza Bento

AMAZONAS

Manaus

Hospital Universitário Getúlio Vargas

ACRE

Rio Branco

Fundação Hospital do Acre

RONDÔNIA

Porto Velho

Hospital de Base Ary Pinheiro

AMAPÁ

Macapá

Hospital de Especialidades de Macapá

PARÁ

\section{Belém}

Fundação da santa Casa de Misericórdia do Pará Hospital Universitário João de Barros Barreto

TOCANTINS

Palmas

Pró-Saúde - Ass. Benef. De Assistência Social

MATO GROSSO

Cuiabá

Hospital Universitário Júlio Muller

MATO GROSSO DO SUL

Campo Grande

Hospital Universitário Federal de Mato Grosso do Sul

Santa Casa de Campo Grande

DISTRITO FEDERAL

Brasilia

Hospital da Universidade de Brasilia

Hospital Regional da Asa Norte - HRAN

Sobradinho

Hospital Regional de Sobradinho

GOIÁS

Goiânia

Hospital das Clínicas da Universidade Federal de Goiás

Santa Casa de Misericórdia de Goiânia

PIAUí

Teresina

Hospital Universitário Getúlio Vargas

MARANHÃO 
São Luís

Hospital Universitário Pres.Dutra/UFMA

BAHIA

Salvador

Hospital São Rafael

Hospital Universitário Prof. Edgar Santos

Associação obras Sociais Irmã Dulce

CEARÁ

Fortaleza

Hospital Universitário Walter Cantídio

Hospital Geral de fortaleza

Hospital Infantil Albert Einstein

Instituto Dr. José Frota

Hospital Messejana

SERGIPE

Aracajú

Hospital Universitário Federal de Sergipe

ALAGOAS

Maceió

Hospital Universitário Prof. Alberto Nunes

PERNAMBUCO

Recife

Hospital Getúlio Vargas/Fundação de Saúde Amaury de Medeiros Hospital da Restauração

Hospital Universitário Oswaldo Cruz

Hospital das Clínicas da Universidade Federal de Pernambuco

Hospital da Universidade de Pernambuco

PARAÍBA

João Pessoa

Hospital Universitário Lauro Wanderley

Campina Grande

Hospital Universitário Alcides Carneiro

RIO GRANDE DO NORTE

Natal

Hospital Universitário Onofre Lopes

RIO GRANDE DO SUL

Porto Alegre

Hospital Moinhos de Vento

Irmandade Sta. Casa de misericórdia de Porto Alegre

Hospital de Clínicas de Porto Alegre

Hospital Nossa Senhora da Conceição

Hospital São Lucas

Santa Maria

Hospital Universitário setor Centro UFSM/FATEC

Pelotas

Fundação de Apoio Universitário - FAU/RS 
Hospital Universitário São Francisco de Paula

SANTA CATARINA

Florianópolis

Hospital Universitário Polydoro Ernani de S. Tiago

Hospital Governador Celso Ramos

PARANÁ

Curitiba

Hospital das Clínicas da Universidade Federal do Paraná

Hospital Universitário Evangélico

Hospital Nossa Senhora das Graças

Maringá

Hospital Universitário Regional de Maringá

Londrina

Hospital Universitário Regional Norte do Paraná

MINAS GERAIS

Belo Horizonte

Hospital de Clínicas da Universidade Federal de Minas Gerais

Hospital felício Rocho

Flemig - Hospital João XXIII

Hospital Governador Israel Pinheiro

Juiz de Fora

Hospital da Universidade Federal e Juiz de Fora

Uberaba

Hospital E.F.M. Triângulo Mineiro

Uberlândia

Hospital de Clínicas de Uberlândia

Pouso Alegre

Hospital das Clínicas Samuel Libânio

ESPÍRITO SANTO

Vitória

Hospital Universitário Cassiano A. de Morais

RIO DE JANEIRO

Rio de Janeiro

Hospital São Vicente de Paulo

Hospital Servidores do Estado do Rio de Janeiro

Hospital Geral de Bonsucesso

Hospital Universitário Pedro Ernesto

INCA - Instituto Nacional do Câncer

Hospital Universitário Clementino Fraga Filho

Hospital Naval Marcílio Dias

Niterói

Hospital Universitário Antônio Pedro

SÃO PAULO - INTERIOR

Botucatu

Faculdade de Medicina de Botucatu 


\author{
Campinas \\ Hospital das Clínicas da Univ. Estadual de Campinas \\ Hospital Municipal Dr. Mário Gatti \\ Catanduva \\ Fundação Padre Albino \\ Jundiaí \\ Hospital de Caridade São Vicente de Paulo \\ Osasco \\ Hospital Municipal Antônio Giglio \\ Marilia \\ Faculdade de Medicina de Marília \\ Ribeirão Preto \\ Hospital das Clínicas da Fac. Med. De Ribeirão Preto \\ São José do Rio Preto \\ Fund. Fac. Medicina. de São José do Rio Preto \\ Santos \\ Hospital Ana Costa S.A. \\ Sorocaba \\ Hospital Santa Lucinda \\ SÃO PAULO - CAPITAL \\ São Paulo \\ Hospital Albert Einstein \\ Hospital sírio Libanês \\ Casa de Saúde Santa Marcelina \\ Hospital das Clínicas da FMUSP \\ Irmandade da Santa Casa de Misericórdia de São Paulo \\ Hospital São Paulo \\ Fundação Adib Jatene \\ Hospital do Servidor Público Municipal \\ Instituto de Radiologia da FMUSP \\ Instituto da Criança da FMUSP \\ Hospital Municipal Dr Cármino Caricchio \\ Associação Cultural e Científica Heliópolis \\ Fundação Antônio Prudente \\ Hospital Brigadeiro \\ Hospital Alípio Correa Neto \\ Hospital Universitário - USP \\ Autarquia Hospital Municipal Reg. de Jabaquara \\ Autarquia Hospital Municipal Reg. de Campo Lindo \\ Conjunto Hospitar do Mandaqui \\ Hospital do Servidor Público Estadual
}


ANEXO 2 - PROGRAMA DE AUDITORIA DE NOTIFICAÇÕES DA ANVISA

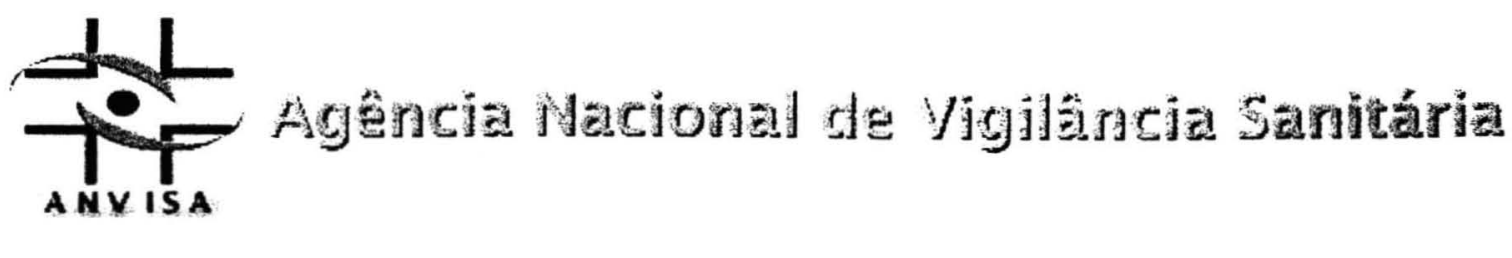

Programa de auditoria de notificações

\section{Áreas disponiveis}

Programa de auditoria da GVISS.

lovigilância Programa de auditoria da Tecnovigilância.

nacovigilância Programa de auditoria da Farmacovigilância.

stigacăo Programa de autitoria da Investigação.

FARMACOVIGILÂNCIA - Programa de auditoria de notificações Acesso ao sistema.

Alterar minha Senha Sair

Acesso ao sistema de Notificacōes

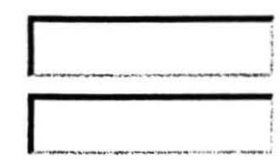

Digite seu eMail, ele é sua identificação neste sistema. Digite sua senha, minúsculas e maiúsculas não fazem diferença. 
ANEXO 2 - Programa de auditoria de notificações da ANVISA (Continuação)

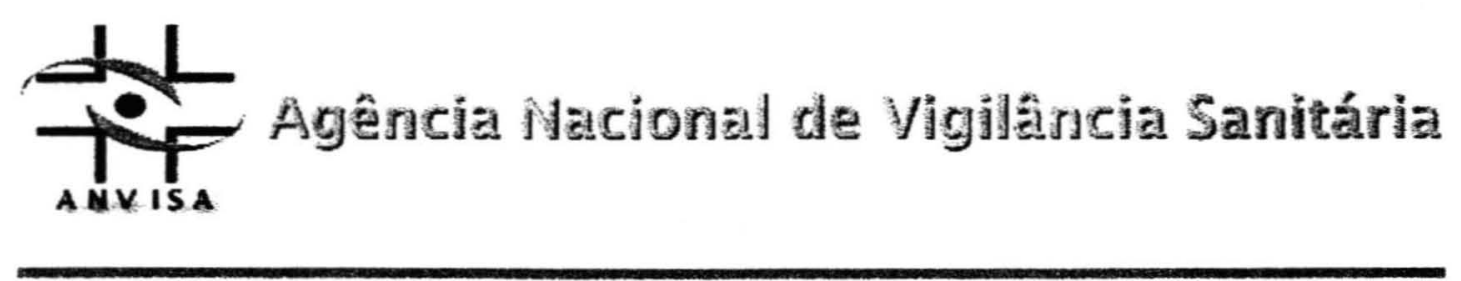

TECNOVIGILÂNCIA - Programa de auditoria de notificações

Acesso ao sistema.

Alterar minha Senha Sair

Acesso ao sistema de Notificaçes

e-Mail

Senha

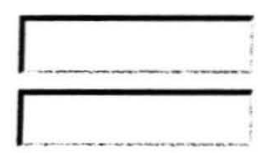

Digite seu eMail, ele é sua identificação neste sistema. Digite sua senha, minúsculas e maiúsaulas não fazem diferença.

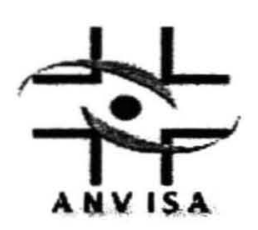

Agếncia Macional de Vigilância Sanitária

INVESTIGAÇÃO - Programa de auditoria de notificações

Acesso ao sistema.

Alterar minha Senha Sair

lail

tha

Acesso ao sistema de Notificaçōes

Digite seu eMail, ele é sua identificação neste sistema. Digite sua senha, minúsculas e maiúsculas não fazem diferença. 


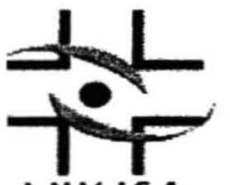

\section{Agkencia dacioral de Mgiglância Sanitária}

A NVISA

\section{ARMACOVIGILÂNCIA - Programa de auditoria de notificações} etalhes da notificação.

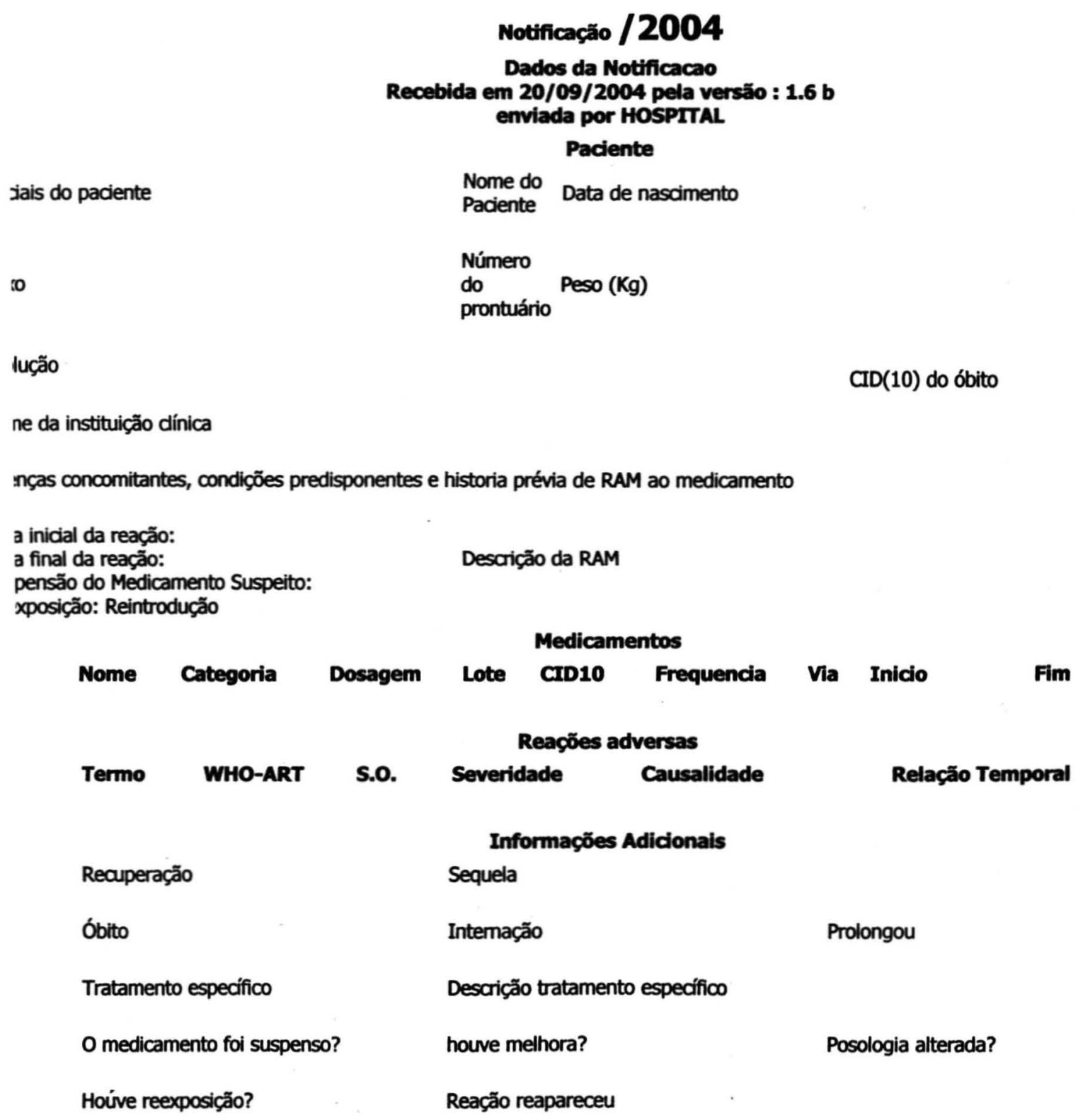

ou Idade

Data da Reação 
Primeira notificação do caso?

Foi notificado para a indústria?

Idade gestacional

Dados do notificador (preenchido no SINEPS)

Notificador

Categoria profissional

Conselho/Número

Cidade/UF

Telefone

eMail 
ANEXO 4 - FICHA DE NOTIFICAÇÃO DE TECNOVIGILÂNCIA

\section{Agência Nacional de Vigłância Sanitária}

\section{TECNOVIGILÂNCIA - Programa de auditoria de notificações}

\section{Detalhes da notificação.}

$\begin{array}{llc} & \begin{array}{c}\text { Notificagão / } 2004 \\ \text { Dados da Notificacao de Equipamento médico } \\ \text { Identificagäo }\end{array} \\ \text { Estabelecimento } & \text { Data Ocorrencia }\end{array}$

Produto

Fabricante

Modelo

Qtd Ocorrencias

Número na ANVISA

Lote

\section{Ocorrência}

O ocorrido foi verificado por Áreas em que ocorreu:

O que aconteceu...

Causa detectada, portanto descreveu o seguinte...

\section{Providências}

Providências tomadas após detectada a causa

Levou agravos a saúde? Poderia levar a agravo?

Produto era descartável?

Na validade de

fabricação?

Usuário

Prioridade
As consequencias poderiam ser...

\section{Artigos, Kit ou ortopédicos}

Quantas vezes foi usado antes do incidente?

Na validade de esterilização?

$$
\begin{aligned}
& \text { Dados adicionais } \\
& \text { versão do programa }
\end{aligned}
$$

Situaçăo

Atividades já executadas nesta notificaça

Assunto
Recomendacöes cumpridas?

Hospital

Nova situação 
ANEXO 5 - FICHA DE NOTIFICAÇÃO DA INVESTIGAÇÃO (QUEIXA TÉCNICA)

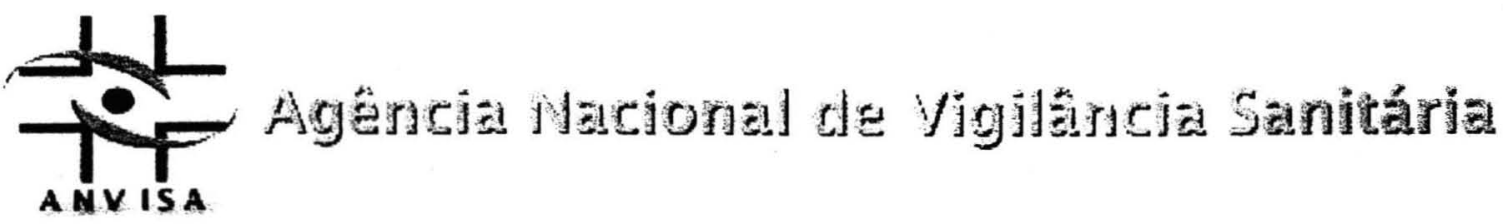

INVESTIGAÇÃO - Programa de auditoria de notificações

Detalhes da Queixa Técnica.

\begin{tabular}{llll} 
& & $\begin{array}{c}\text { Queixa } / 2004 \\
\text { Dados da Notificacao } \\
\text { Recebida em } \\
\text { enviada por } \\
\text { Medicamento : } \\
\text { Medicamento }\end{array}$ \\
substância Ativa & Lote & Categoria & Concentração \\
Forma farmacêutica & Data de fabricação & Data de Validade & Linha Farmacêutica \\
\hline & Número do registro & Fabricante & CNPJ
\end{tabular}

Motivo da Queixa

Motivo

Detalhe

Nome do notificador

Categoria Profissional

Notificador

Endereço

Muniápio

UF

eMail

Gerente de Risco

Telefone

Informações adicionais

Data da Notificação:

Outras informaçōes

Dados adicionais

Usuário 
ANEXO 6- JANELA PARA SELECIONAR AMOSTRAGEM FARMACOVIGILÂNCIA

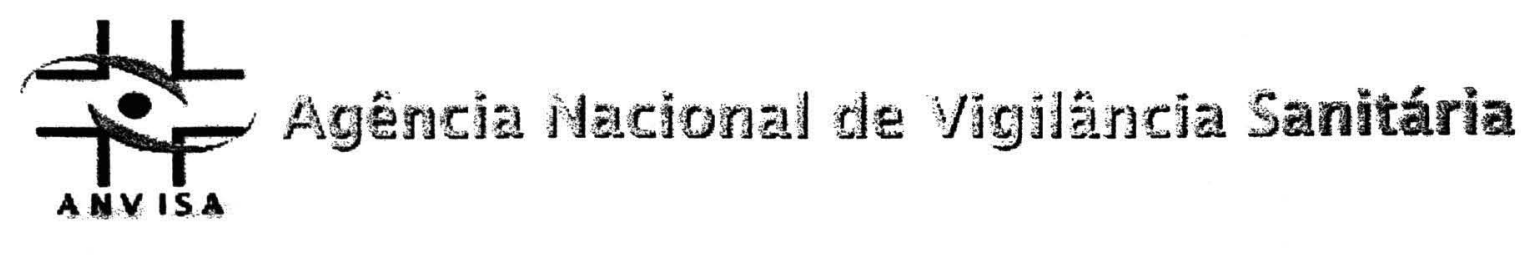

FARMACOVIGILÂNCIA - Programa de auditoria de notificações

Relatórios e consultas do Sistema.

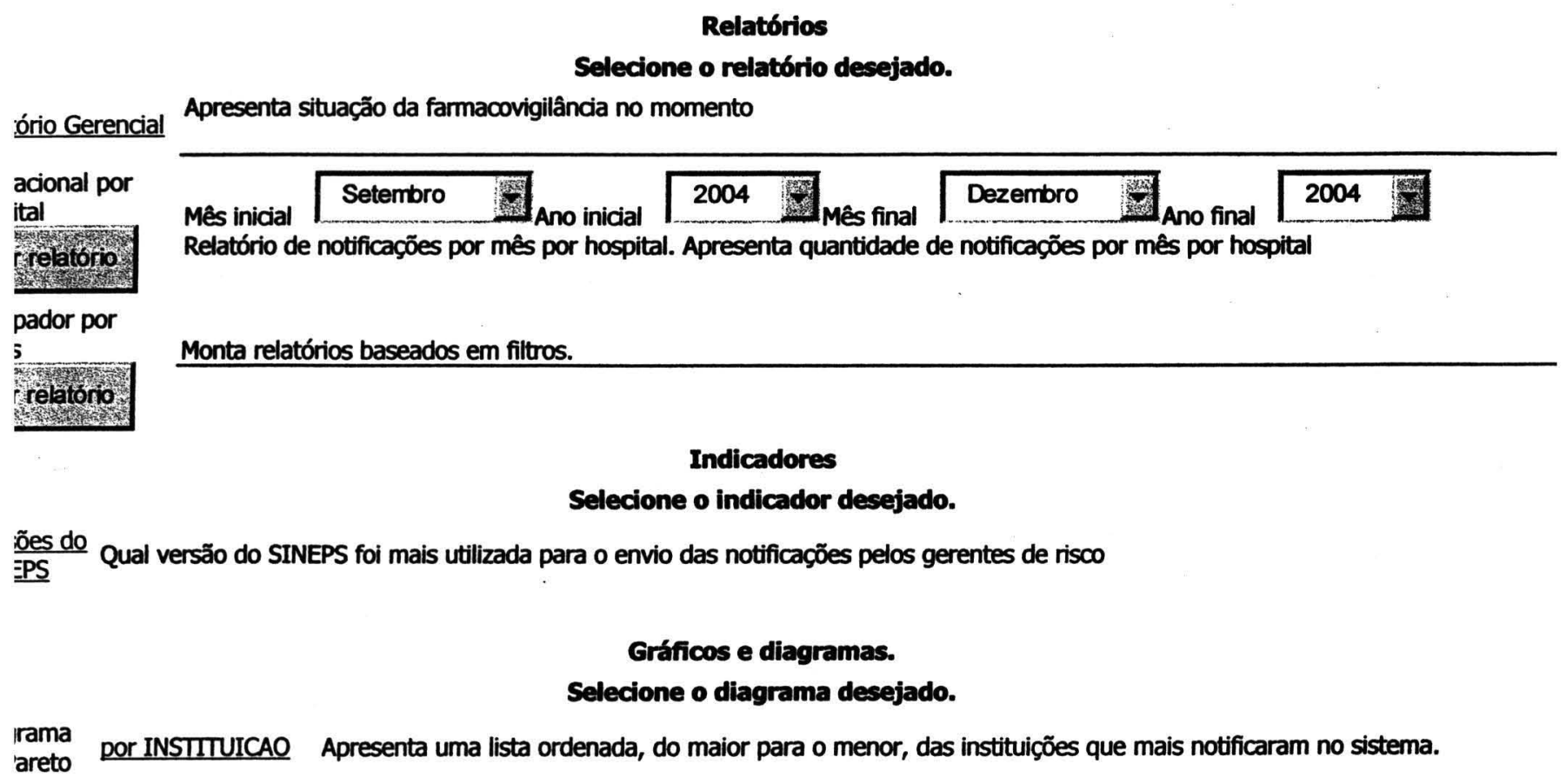


FARMACOVIGILÂNCIA - Programa de auditoria de notificações

Pesquisar notificações no sistema.

Pesquisar

Preencha os campos desejados para a pesquisa e clique em pesquisar.

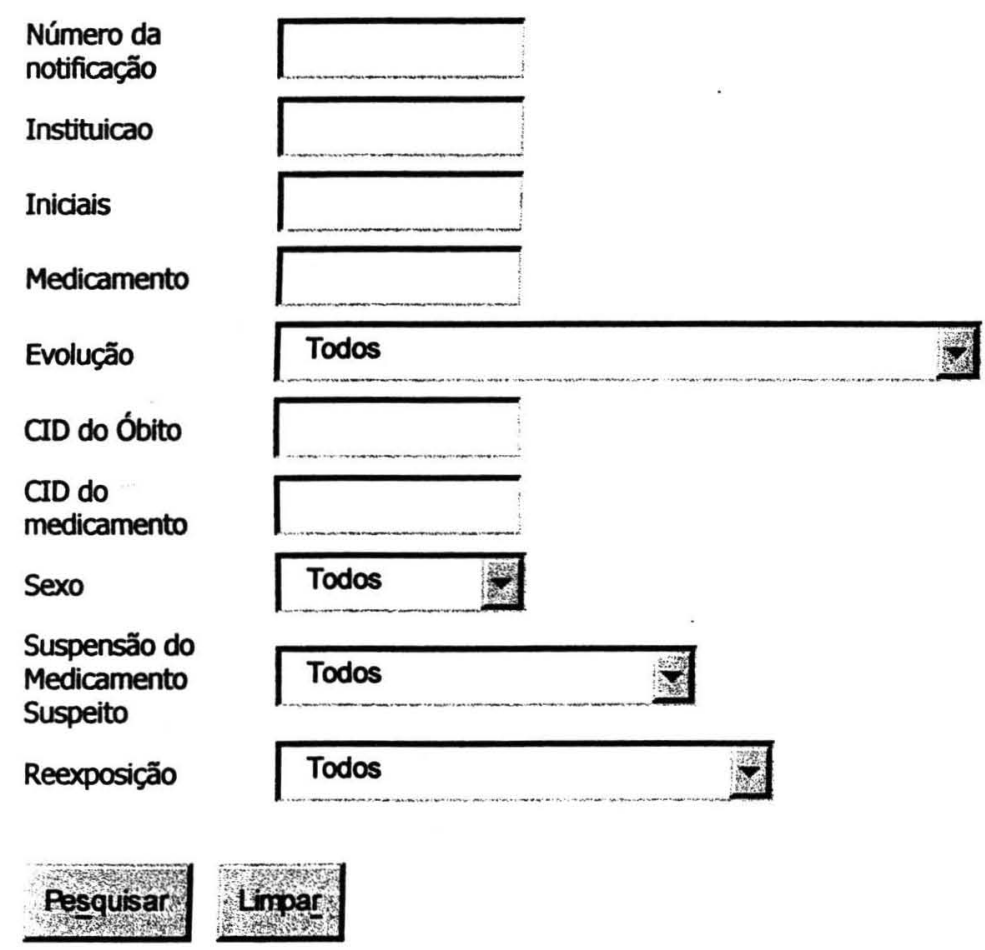

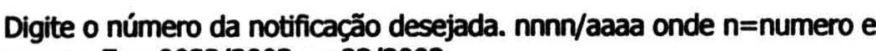
a=ano. Ex.: 0023/2003 ou 23/2003.

O nome da instituicao, hospital ou parte dele.

As inciais do paciente ou parte dela.

O nome do medicamento desejado.

Escolha a restrição para a evolução do paciente.

O CID do óbito, ou parte dele, que deseja restringir.

o CID do medicamento, ou parte dele, que deseja restringir.

Escolha o Sexo do paciente.

Escolha a restrição para a suspenção.

Escolha a restrição para a Reexposição. 


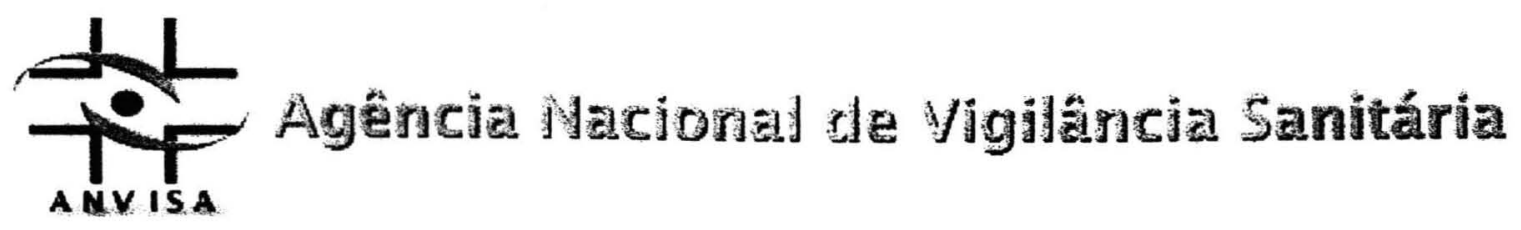

\section{TECNOVIGILÂNCIA - Programa de auditoria de notificações}

\section{Relatórios e consultas do Sistema.}

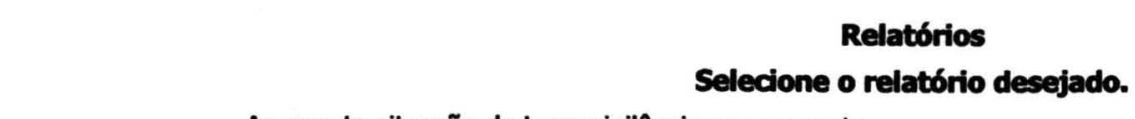

Gerencial Apresenta situação da tecnovigilância no momento
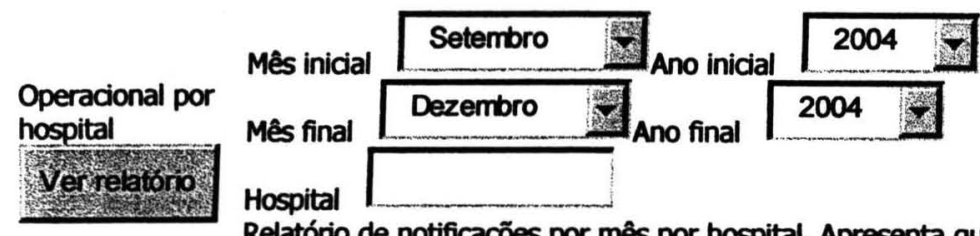

Relatório de notificaçōes por mês por hospital. Apresenta quantidade de notificaçoes por mês por hospital

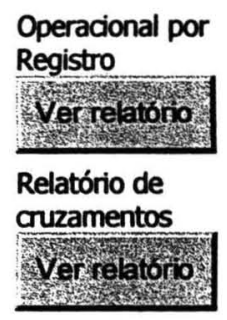

INDICADORES

por EMPRESA

Diagrama por HOSPITAL de Pareto

por versões do SINEPS

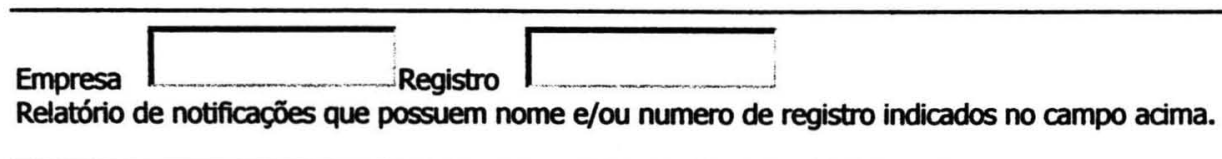

Busca o agrupamento das notificações por restricōes conjuntas.

\section{Indicadores}

Selecione 0 indicador desejado.

Indicadores da Tecnovigilância

\section{Gráficos e diagramas.}

Selecione o diagrama desejado.

Apresenta uma lista ordenada, do maior para o menor, das empresas com notificacōes neste sistema. Apresenta uma lista ordenada, do maior para o menor, dos notificantes e a quantidade de suas notificagóes neste sistema.

Mostra qual versão do SINEPS está sendo mais usada pelos gerentes de risco para enviar as notificaçōes. 
ANEXO 8 -. JANELA PARA SELECIONAR AMOSTRAGEM - INVESTIGAÇÃO

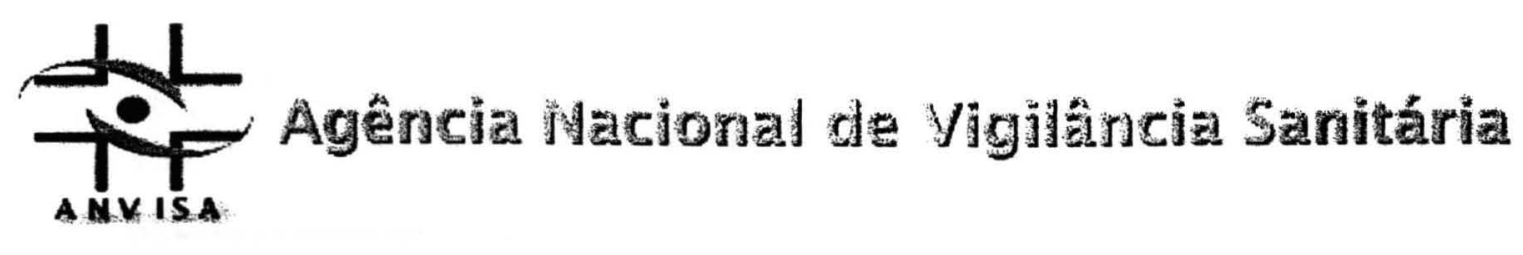

INVESTIGAÇÃO - Programa de auditoria de notificações

Relatórios e consultas do Sistema.

Selecione o relatório desejado.

Relatórios

Agrupador por filtros

vericelorio

Monta relatórios baseados em filtros.

cerreatorio

Gráficos e diagramas.

Selecione o diagrama desejado.

POI EMPRESA

Verrelation

Verreatoro

Apresenta uma lista ordenada, do maior para o menor, das empresas com queixas técnicas neste sistema.

Diagrama de

Pareto

por versões do SINEPS

Verretatoro

Merreatoro

Mostra qual versão do SINEPS está sendo mais usada pelos gerentes de risco para enviar as queixas técnicas. 
Anexo.8 (continuação): Filtro da investigação

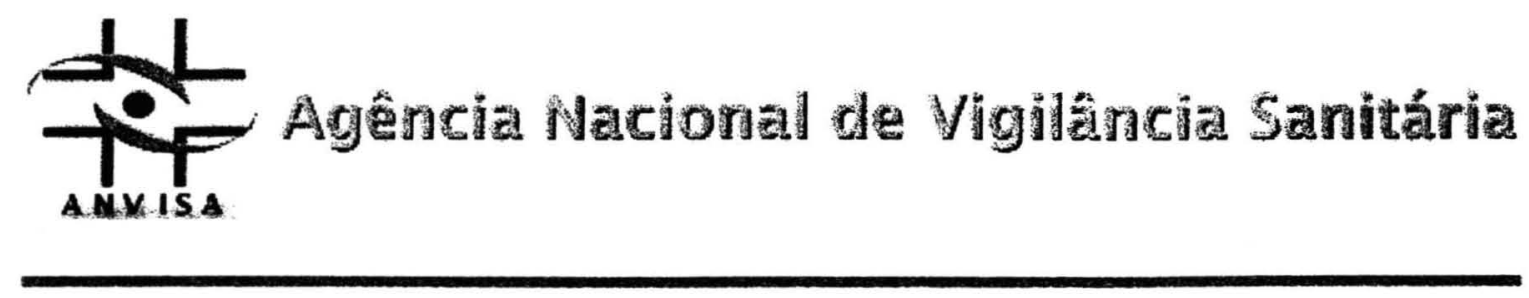

INVESTIGAÇÃO - Programa de auditoria de notificações

Relatórios e consultas do Sistema.

Voltar

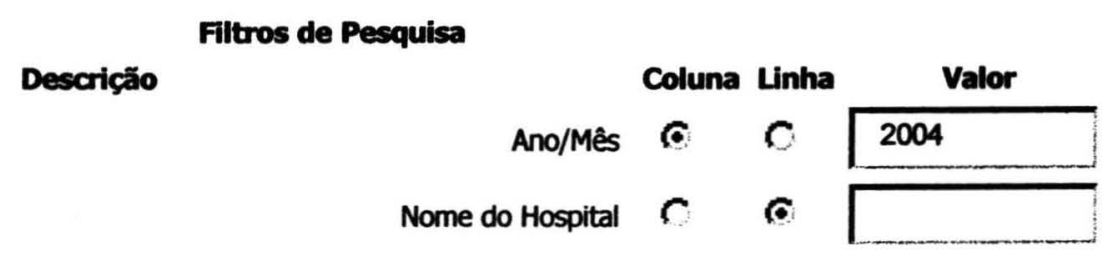


Anexo 9 - Definições das categorias de produtos médicos (MINISTÉRIO DA SAÚDE, 1994; ANVISA, 2001b).

Equipamento de diagnóstico - equipamento, aparelho ou instrumento de uso médico, odontológico ou laboratorial, destinado a detecção de informações do organismo humano para auxílio a procedimento clínico.

Equipamento de terapia - equipamento, aparelho ou instrumento de uso médico ou odontológico, destinados a tratamento de patologias, incluindo a substituição ou modificação da anatomia ou processo fisiológico.

Equipamento de apoio médico-hospitalar - equipamento, aparelho ou instrumento de uso médico, odontológico ou laboratorial destinado a fornecer suporte a procedimentos diagnósticos, terapêuticos ou cirúrgicos.

Materiais e artigos descartáveis - são os materiais e artigos do uso médico, odontológico ou laboratorial, utilizáveis somente uma vez de forma transitória ou de curto prazo.

Materiais e artigos implantáveis - são os materiais e artigos de uso médico ou odontológico, destinados a serem introduzidos total ou parcialmente no organismo humano ou em orificio do corpo, ou destinados a substituir uma superfície epitelial ou superficie do olho, através de intervenção médica, permanecendo no corpo após o procedimento por longo prazo, e podendo serem removidos unicamente por intervenção cirúrgica. 
Materiais e artigos de apoio médico-hospitalar - são os materiais e artigos de uso médico, odontológico ou laboratorial, destinados a fornecer suporte a procedimentos diagnósticos, terapêuticos ou cirúrgicos.

Produtos para diagnóstico de uso "in-vitro" - reagentes, instrumentos e sistemas, junto com as instruções para seu uso, que contribuam para realizar uma determinação qualitativa, quantitativa ou semi-quantitativa de uma amostra biológica e que não sejam destinados a cumprir função anatômica, física ou terapêutica alguma; que não sejam ingeridos, injetados ou inoculados em seres humanos e que são utilizados unicamente para prover informação sobre espécimes extraídos do organismo humano.

Equipamentos, materiais e artigos de educação física, embelezamento ou correção estética. 
Anexo 10 - Critérios de risco para produtos médicos (MINISTÉRIO DA SAÚDE, 1994; ANVISA, 2001b).

Produtos médicos classe I: são produtos que por dispensarem o emprego de procedimentos e técnicas especiais de produção e cuidados ou precauções em seu uso ou aplicação, representam baixo risco intrínseco à saúde de seus usuários, seja paciente ou operador.

Produtos médicos classe II: são os produtos médicos que apesar de dispensarem o emprego de procedimentos e técnicas especiais de produção, necessitam de cuidados ou precauções em seu uso ou aplicação, representando médio risco intrínseco à saúde de seus usuários, seja paciente ou operador.

Produtos médicos classe III: são os produtos que por necessitarem do emprego de procedimentos e técnicas especiais de produção, bem como de cuidados ou precauções em seu uso ou aplicação, representam alto risco intrínseco à saúde de seus usuários, seja paciente ou operador.

Produtos médicos classe IV: todos os produtos médicos invasivos cirurgicamente especialmente: àqueles para diagnóstico, monitoração ou correção de disfunção cardíaca ou do sistema circulatório central, através de contato direto com estas partes do corpo, aqueles utilizados em contato direto com o sistema nervoso central, os que administram energia na forma de radiações ionizantes e os que exercem efeito biológico ou são totalmente ou em grande parte absorvidos. 